\title{
Assessment of Historical and Future Water Availability in Himalayan Tamor River Basin Nepal Utilizing CMIP5 CNRM Climate Model Experiments
}

\section{Bishal Pokhral}

IIT Roorkee: Indian Institute of Technology Roorkee

Vishal Singh ( $\square$ shalu.ashu50@gmail.com )

National Institute of Hydrology https://orcid.org/0000-0001-6023-7075

\section{S. K. Mishra}

IIT Roorkee: Indian Institute of Technology Roorkee

\section{Sanjay K Jain}

National Institute of Hydrology

\section{Pushpendra K Singh}

National Institute of Hydrology

Joshal K Bansal

National Institute of Hydrology

\section{Research Article}

Keywords: Tamor Basin, SWAT Modeling, Water Availability, Climate change, Dependable Flow, CMIP5 CNRM

Posted Date: November 2nd, 2021

DOI: https://doi.org/10.21203/rs.3.rs-855294/v1

License: (c) (1) This work is licensed under a Creative Commons Attribution 4.0 International License. Read Full License 
1 Assessment of Historical and Future Water Availability in Himalayan Tamor River Basin

2 Nepal Utilizing CMIP5 CNRM Climate Model Experiments

$3 \quad{ }^{1}$ Bishal Pokhral, ${ }^{2}$ Vishal Singh*, ${ }^{1}$ S. K. Mishra, ${ }^{2}$ Sanjay Kumar Jain, ${ }^{2}$ Pushpendra Kumar 4 Singh, ${ }^{2}$ Joshal Kumar Bansal

$5{ }^{1}$ Water Resources Development and Management, Indian Institute of Technology, Roorkee-

6 247667, Uttarakhand, India

$7{ }^{2}$ Water Resources System Division, National Institute of Hydrology, Roorkee-247667,

8 Uttarakhand, India

9

10

11

12

*Corresponding Author - Dr. Vishal Singh

13

Email - vishal18.nihr@gov.in

14

15

16

17

18

19

20 
Assessment of Historical and Future Water Availability in Himalayan Tamor River Basin Nepal Utilizing CMIP5 CNRM Climate Model Experiments

${ }^{1}$ Bishal Pokhral, ${ }^{2}$ Vishal Singh*, ${ }^{1}$ S. K. Mishra, ${ }^{2}$ Sanjay Kumar Jain, ${ }^{2}$ Pushpendra Kumar Singh, ${ }^{2}$ Joshal Kumar Bansal

${ }^{1}$ Water Resources Development and Management, Indian Institute of Technology, Roorkee247667, Uttarakhand, India

${ }^{2}$ Water Resources System Division, National Institute of Hydrology, Roorkee-247667, Uttarakhand, India

Abstract: In this study, the assessment of water availability under climate changing environment has been done in the Himalayan Tamor River Basin, Nepal using physically based, spatially distributed, a continuous model 'Soil and Water Assessment Tool' (SWAT). The hydrological simulation and projection have been performed in the historical (1996-2007) and future times (e.g. 30s, 40s, 50s, 60s, 70s, 80s, 90s). The climate change impact assessment on the hydrology of Tamor river basin has been performed utilizing the CMIP5 CNRM climate model datasets (with RCP4.5 and RCP8.5). The model calibration and parameterization uncertainty evaluation in the simulated and projected flows were done in SWATCUP using SUFI2 algorithm. The results obtained from the model calibration (1996-2004) and validation (2005-2007) showed a reliable estimate of daily streamflow for calibration period $\left(\mathrm{R}^{2}=0.85\right.$, $\mathrm{NSE}=0.85$ and $\mathrm{PBIAS}=-2.5)$ and validation period $\left(\mathrm{R}^{2}=0.87, \mathrm{NSE}=0.85\right.$ and $\left.\mathrm{PBIAS}=-5.4\right)$. The average annual water yield at the main outlet of the basin is computed as $1511.13 \mathrm{~mm}$, and the total annual quantity is recorded as $6.25 \mathrm{BCM}$. The average annual precipitation over the seleced river basin is projected to be increased in all scenarios. The stations at higher altitude show more temperature rise than those at a lower elevation and thus there would be minimal snowfall has been projected in the basin by 2100 AD under both scenarios (RCP4.5 and 
RCP8.5). It is expected that the flow pattern in the future would be similar to the baseline pattern under all scenarios. The baseflow will be dramatically increased in all scenarios, but the lowest flow month would be shifted from March to February. Since the base flow during lean months would be increased in future as projected by all scenarios, there would not be adverse impacts on higher percentile flows. This study would be useful for the assessment of the possibility of storage type or run-off-river type hydro-project in the basin in terms of water availability.

Keywords: Tamor Basin; SWAT Modeling; Water Availability; Climate change; Dependable Flow, CMIP5 CNRM

\section{Introduction}

The water resource is one of an essential input to the growth and well-being of the nation. Nepal is a mountainous country with more than 6000 rivers, with a total average yearly flow of about 225 billion cubic meters (WECS, 2011). As other mountain originated river of Nepal, Tamor river is being planned for its extensive use especially in hydropower generation and highly linked for inter-basin transfer being excess in the basin than demand. Nepal has realised as a national topmost and highly prioritised issue of water resources for the country prosperity and development (Chhetri et al., 2020; Sharma and Shakya, 2006). But the hydrology of the rivers in Himalayan basin is predicted to be more vulnerable because of the seasonal, latitudinal and altitudinal shifting of the freezing line due to the effects of the climate change (Singh et al., 2021a; Singh and Goyal, 2017; Jones, 1999).

The rate of snowfall can be determined for precipitation with the record of daily air temperature. (Pradhanang et al., 2011). The rising of atmospheric temperature is the leading cause of the declining the quantity of snowfall in the Himalayan regions which further result in the rapid melting of snow-glaciers and reduces the snow cover durations (Singh et al., 2021a, 
2021b; Singh and Bengtson, 2004). The reduction of the snow-to-rain ratio causes wetter monsoon and drier lean flow seasons which has a very adverse effect on the runoff river type hydropower potential of the mountain rivers (Singh et al., 2021b; Agrawala et al., 2003).

Nowadays, several hydrological models are available for an efficient assessment of water resources and to find out the impact of climate and soil properties on hydrology and water resources. (Shrestha et al., 2015; Moradkhani and Sorooshian, 2009) defined a model as a simplified representation of the real-world system.

The best model is that which gives results proximity to reality with the use of least possible parameters and model complexity (Devia et al., 2015). Among different process-based semidistributed models, SWAT which can perform on HRU level has been used extensively and globally for the simulation and projection of various hydrological components (Singh et al., 2019; Singh and Goyal, 2017; Jain et al., 2017). Many studies provided an overview of the model performance statistics for hydrological processes in numerous SWAT applications (Himanshu et al., 2017; Pandey et al., 2015; Gassman et al., 2014). Several studies demonstrated the model performance in the projection of hydrological components in Himalayan basins utilizing multi-model climate datasets to assess the impact of climate change (Singh et al., 2019; Singh and Goyal, 2017). Mishra et al. (2018) explored the effects of climate change on streamflow in the Bheri river basin Nepal with three GCMs under RCP4.5 and RCP8.5 and predicted that due to increase in maximum and minimum temperature in future, the streamflow increases.

Kundu et al. (2017) studied individual and combined effects of land-use and climate change on the Narmada River basin, India and concluded that the climate change has more influence on water yield and land-use change was affecting more on evapotranspiration and overland flow. A very few studies analyzed that the supply and demand of water in the Himalayan basin is 
affected by the effects of climate changes on glacier dynamics (Singh et al., 2021b; Singh et al., 2019a; NRCNA 2012). Singh and Goyal (2016) analysed temperature and precipitation in Tista river catchment in India with CMIP5 climate model datasets and observed that there were substantial variations in streamflow and precipitation in terms of their rates, intensities and frequencies in observed as well as future periods.

Since very limited studies have been recorded to assess the future water availability under the influence of climate change in snow and glacial dominated mountainous terrain of Nepal, the reviews of various kinds of literature mentioned above encouraged for the application of the SWAT model for hydrologic simulation and projection of various hydrological components over the Himalayan Tamor River basin, Nepal. The SWAT model has been performed on the daily scale, but the outcomes have been studied at daily, monthly and annual scales. The undertainty in the modeling outcomes has been assessed during model calibration with reference to observed streamflow data utilizing SUFI-2 optimization method which is inbuilt in SWATCUP. The uncertainty estimation using SUFI-2 was done by many researchers, which is found effective in the improvements of projected modeling scenarios using SWAT (Kumar et al., 2017; Singh and Goyal, 2017). Since a large size Dam of about $208 \mathrm{~m}$ is proposed at the outlet location of the selected river basin for the construction of Tamor Storage Hydroelectric Project. However, this is not a hydrological station and does not have a measured dataset of any periods. Thus, the simulated discharge at the outlet obtained from this study would be very useful for the generation of hydropower potential in the selected river basin. Similarly, the predicted future streamflow will further help to understand the future pattern and future water potential of the river. The water availability over the basin has been assessed by computing the probabilistic dependable flows in historical and future times by constructing Flow Duration Curves (FDCs). The climate change impacts on the water availability have been assessed utilizing the CMIP5 CNRM-CM5 climate model experiments (with RCP4.5 and RCP 8.5). 


\section{Study Area}

120

121

122

123

124

125

126

127

Koshi river is the largest river of Nepal, and among its seven major sub-basins, the Tamor subbasin is the easternmost sub-basin that originates from the Himalayas of Kanchanjunga and joins with Arun and Sunkoshi to form giant Saptakoshi which is the major tributary of Ganga River in India. The basin area considered in this study is $4860.5 \mathrm{Km} 2$ from Taplejung, Terhathum and Panchthar districts of Province no. 1, Nepal. The basin has a very diverse climate since the elevation ranges from $350 \mathrm{~m}$ to $7526 \mathrm{~m}$ above mean sea level within $150 \mathrm{~km}$ length. The south-east monsoon is the most dominant climatic influence and is responsible for almost monsoon in the basin. The difference between the warm and humid summer and the extremely cold winter becomes remarkable with the increase in altitude from South to North. The mean annual basin precipitation is around $2305 \mathrm{~mm}$ (a result of this study). Although, most of the precipitation for this region is concentrated during the monsoon months, the snowcovered and glaciated upper reaches of the basin contribute meltwater to the streamflow throughout the year. Furthermore, other spring sources in the hilly and mountain terrains provide considerable perennial water discharge in the basin. Besides, freshwater streams, 261 glaciers and 356 glacial lakes are recorded within the basin area (ICIMOD,2001). In this study, Majhitar station (catchment area- $4132 \mathrm{~km}^{2}$ ) is calibrated whose average annual observed flow for (1996-2004) is $265.5 \mathrm{~m}^{3} / \mathrm{s}$ (data from DHM, Nepal). The main outlet of the basin in this study corresponds to the Dam site of proposed Tamor river hydropower project of $762 \mathrm{MW}$ (NEA Nepal, 2018). But this is not a hydrological station, and hence the discharge data at Majhitar will be calibrated in this study for the estimation of simulated flow at this outlet. The future predicted discharge under various scenarios in this study would provide crucial information on future water availability at the dam location and help in making sustainable planning for reservoir operation.

\section{**Insert Figure 1 here**}




\section{Data Inputs Utilized}

145

It is always essential to use all relevant and high-quality data to obtain a good result. The essential input datasets are digital elevation model (DEM), soil map, land use and land cover (LULC) map, slope map, weather generator data and observed discharge were used for the SWAT modeling simulation and calibration (Figure 2).

In this study, the SRTM DEM of $30 \mathrm{~m} \times 30 \mathrm{~m}$ resolution has been used to delineate the streams, sub-basins, slope, basin boundary and other watershed parameters (https://earthexplorer.usgs.gov/). LULC data was obtained from the International Centre for Integrated Mountain Development (ICIMOD) and then it was reclassified using crops and land use types that were defined within the model databases and used for the creation of multiple Hydrologic Response Units (HRUs). The watershed area of the Tamor river is mostly occupied by dense forest to deciduous forest, agricultural and snow-covered area (Figure 2). The textural and physicochemical properties of soil such as soil texture, hydraulic conductivity, water content, bulk density, organic matter content etc. for different layers of each soil type are required for SWAT modeling.

\section{**Insert Figure 2 here**}

The soil map and soil parameters were obtained from Food and Agricultural Organization (FAO) with a scale of $1: 50,00,000$ for the study area (http://www.fao.org/geonetwork/srv/en/metadata.show?id=14116). Dystic Cambisols (Bd34$2 \mathrm{bc}$ ) is found the dominant soil class in the basin area followed by Lithosols (I-Bh-U-c-3717) (Figure 2). The slope map of the study area was prepared from the SRTM DEM and then it was re-classified into five different classes (Figure 2a). The Tamor river basin is mostly characterised by mild to a high steep slope. 
The daily meteorological data from 1993-2007 were used by the SWAT model for the analysis of water balance at HRU scale and its aggregation was done at sub-basin and watershed scale. The daily precipitation data of twelve stations, five temperature stations and measured discharge data of Majhitar outlet were obtained from the Department of Hydrology and Meteorology (DHM), Nepal have been used for the study analysis. The location of the meteorological and hydrological stations within or in the proximity of the basin has shown in the Figure $2 b$. The auto simulation option available in ArcSWAT was chosen for remaining data input, such as wind speed, relative humidity, and solar radiation, which utilizes the datasets from the weather generator of SWAT. Before using the rainfall and temperature data in the application, it was checked for continuity, and missing rainfall and temperature records were filled by the data data-gaps filling method such as multi-linear regression (MLR) and Inverse Distance Weightage (IDW) methods (Singh and Xiaosheng, 2019; Chen et al., 2017).

\section{Methodology}

\subsection{SWAT Modeling For Snow/Glacier Induced Basin}

SWAT requires number of data inputs viz. DEM, LULC map, soil map, slope (Figure 4a) and hydro-meteorological datasets to setup the model. The present study basin corresponded to snow and glaciers and therefore, several additional parameters relevant to snow/glacier hydrology were also taken into consideration with parameters related to rainfall-runoff modeling. In this study, the basin, sub-basins, and drainage networks were delineated with the help of ArcSWAT interface using DEM data. The whole study basin was divided into 15 subwatersheds (see Figure 2b). While deciding the sub-basin outlets, important un-gauged locations needing water resource assessment and available river gauging stations were considered. A total of eight LULC classes and four types of soil were defined (Figures $4 \mathrm{c}$ and 4d). The land slope of the study was classified into five multiple classes and overlaid with the 
LULC and soil map and the threshold value of $8 \%$ each for land use, soil and slope was defined which divided the total watershed into 298 number of hydrologic responsive units (HRUs). Similar subwatershed is characterised by dominant land use, soil type and management practices (Kalcic et al., 2015). Snow cover and snowmelt are simulated separately for each elevation band (Fontaine et al., 2002). The SWAT allows the users to split sub-basins into a maximum of ten elevation bands, but only eight elevation bands were set up for the snow, and glacial dominated sub-basins in higher altitudes with an equal vertical distance from the mean elevation of the centroid of the sub-basins. The model was run considering the following methods of calculation for various hydrological processes; Penman-Monteith method for potential evaporation process, SCS Curve number for surface runoff, initial curve number estimation using soil moisture method, Muskingum method for channel routing.

\subsection{SWAT CUP - Calibration, Model Parametrization and Sensitivity analysis}

The SWAT-CUP, a public domain software which is easily linked to the SWAT interface of GIS, was used for the calibration/ uncertainty or sensitivity analysis. The details about SWATCUP can be read on (Abbaspour, 2015). The SUFI2 model was chosen for its advantages over other algorithms of covering all types of uncertainties like, (a) uncertainty of input variables like precipitation; (b) uncertainty in the concept of the model; (c) uncertainty in the used parameters and (d) uncertainty of observed data. In SUFI-2, the degree of uncertainties is enumerated by a measure specified as the P-factor (i.e. the percent of measured data bracketed by the $95 \%$ prediction uncertainty (95PPU)) and quantify the strength of the uncertainty analysis by R-factor (i.e. the average thickness of the 95PPU band divided by the standard deviation of the measured data). SUFI-2 tends to cover most of the measured data with the smallest possible uncertainty band. (Abbaspour, 2015). In general, hydrological models such as SWAT incorporate many parameters, but only a few of these parameters have sensitive impacts. 
SWAT-CUP has two options for sensitivity analysis, and they are all-at-a time (AAT), i.e.

217 global and one at a time (OAT) sensitivity analysis. In this study, a global sensitivity analysis was chosen since the AAT produces more reliable results than OAT (Abbaspour, 2015). Global sensitivity analysis is determined based on t-stat and p-value (Abbaspour, 2015). At 95\% confidense interval, as per the t-stat test, if the value of parameter exceeds $>2.0$ or less than 2.0, the parameter can be defined as the significant sensitive. While, in case of p-value test, parameters having values $<0.05$ can be defined as significant sensitive (Abbaspour, 2015). In SUFI-2, the calibration was done from 1996 to 2005, and the result from calibration was further validated for 2005 to 2007 at the Majhitar outlet. The optimized parameters after the calibration in SWAT-CUP will be aggregated over the downstream subbasins (14 and 15) to get the reliable predictions at the final outlet location of the selected river basin. The evaluation of model performance or the measure of the degree of fit was done taking three most common objective functions in SWAT CUP, Nash-Sutcliffe efficiency (NSE) (Lin et al., 2017),

$$
\begin{gathered}
R^{2}=\left[\frac{\sum_{i=1}^{i=n}\left(Q_{m, i}-\bar{Q}_{m}\right)\left(Q_{s, i}-\bar{Q}_{s}\right)}{\left[\sum_{i=1}^{i=n}\left(Q_{m, i}-\bar{Q}_{m}\right)^{2} \sum_{i=1}^{n}\left(Q_{s, i}-\bar{Q}_{s}\right)^{2}\right]}\right]^{2} \\
N S E=1-\left[\frac{\sum_{i=1}^{i=n}\left(Q_{m, i}-Q_{s, i}\right)^{2}}{\sum_{i=1}^{i=n}\left(Q_{m, i}-\bar{Q}_{m, i}\right)^{2}}\right] \\
\text { PBIAS }=\left[\frac{\sum_{i=1}^{i=n}\left(Q_{m, i}-Q_{s, i}\right) * 100}{\sum_{i=1}^{i=n} Q_{m, i}}\right]
\end{gathered}
$$


Where, $Q$ is the variable and ' $m$ ' stand for measured and ' $S$ ' stands for simulated values, bar stands for average, and $i$ is the $i^{\text {th }}$ measured or simulated variable. The statistics recommended by (Moriasi et al., 2007) will be used in this study to define SWAT model performance ratings.

\subsection{Computation of Flow Duration Curve (FDC)}

The streamflow variation has been studied over the selected basin in historical and future time with one of the popular methods known as FDC. The FDC is a plot which presents the percentage of time that streamflow at a specific location is likely to equal or exceed some interested prescribed value (Zhang et al., 2018). Streamflow or discharge differs usually over a water year and this unpredictability can be studied by plotting FDCs for the given streams. FDCs, also referred as Discharge Frequency Curve (DFC). If the number of data points is 'N', the plotting position of any discharge (or class value) ' $Q$ ' is

$$
P_{p}=\frac{m}{N+1} X 100 \%
$$

Where, $P_{p}=$ percentage probability of the flow magnitude being equalled or exceeded, $\mathrm{m}$ is the number of the discharge (or class value). The plot of the $Q$ against $P_{p}$ is the flow-duration curve. The slope of the FDC depends upon the interval of data used. In this study, the FDCs have been used to abstract the dependable flow of the observed period, and future flow under various climates change scenarios (Zhang et al., 2018). FDCs will be helpful in the designing the capacity of the reservoir or dam. Similarly, the shifting of flow pattern due to the impact of climate change exploration under those climate change scenarios has been studied for different percentile flow for daily, monthly, and annual basis of different decadal periods.

\subsection{Incorporation of GCM Model Experiments and Future Projections}

For the projection of future streamflow scenarios (21st century), the statistically downscaled and bias-corrected version of precipitation and temperature data by NASA NEXGDDP (at 
CM5 model with moderate and extreme representative concentration pathway (RCP) experimental scenarios (RCP4.5) and RCP8.5, respectively were downloaded (http://cccr.tropmet.res.in/). These data were extracted Python programming and again biascorrected by the quantile mapping (QM) approach using observed precipitation and temperature datasets to remove local bias (Gupta et al., 2020; Gurrapu and Singh, 2019; Singh et al., 2019b).

The selection of the climate model is generally based on the capability of the model to simulate the past and near-present data, this approach of selecting the model is called the past performance approach (Biemans et al., 2013). Based on the performance in South Asia, CNRM-CM5 is one of the best three models that have been suggested by a study (Talchabhadel et al., 2020). Khadel et al. (2018) utilised 38 GCM climate models to analyse the variability of spatiotemporal summer monsoon season (SMS) over the central Himalayas around Nepal and suggested that ACCESS1.0, CNRM-CM5, and HadGEM2-ES as the best models for South Asia. (Abbaspour et al. 2007) program for the water balance study of the basin in general and the snowmelt contribution in the river flow. The RCP4.5 and RCP8.5 pathways used for preparing the fifth assessment report of IPCC were used in this study, which represents the scenarios of stabilisation over greenhouse gas (GHG) emissions. The Python programming platform was used to remove the bias from the historical (1993-2005) as well as future decades of early-century (2030s), mid-century (2060s) and late-century (2090s) for climate variables of rainfall and temperature (maximum and minimum) at the grid-scale $\left(25^{\circ} \times 25^{\circ}\right)$ with reference to observed station-based datasets. Before analysing the changes in future climatic variables, the feasibility of the future climate model datasets (e.g. precipitation and temperature) was

277 checked by comparing the observed and historic model generated raw data of 1993-2007. The 
points along with 'r squared' was used to measure the differences between observed and modelpredicted values (Chai and Draxler, 2014). Finally, the bias-corrected weather data was used to generate the predicted future flows. For generating the future flow for both scenarios, the calibrated SWAT model was run with the fitted parameters values from SWAT-CUP. The overall methodology has shown in Figure 3.

\section{**Insert Figure 3 here**}

\section{Results and Discussions}

Determination of sensitive parameters is the initial stage in the model performance evaluation process of the SWAT model for a given watershed. Based on previous SWAT-CUP studies, a list of 17 potential parameters sensitive to snow/glacier induced flow were prepared, but only 4 parameters were found significant sensitive to the simulated streamflow at the outlet. For this study, during calibration using SUFI-2 method, the NSE was used as an objective function. After running for 15000 number of simulations for calibration in SWAT CUP, the sensitive parameters and the range, as well as the best-fitted values of those parameters were obtained, and the flow was validated by running 1500 number of simulations with same parameters. The list of the 17 sensitive parameters to the snow/glacier induced streamflow along with their bestfitted values, t-stat and p-values in SWAT- CUP calibration have presented in Table 1 . The result confirmed that the Groundwater delay (GW_DELAY) was the most sensitive parameter followed by Baseline alpha-factor (ALPHA_BF). Similarly, other significant sensitive parameters were Effective hydraulic conductivity in main channel alluvium (CH_K2), SCS runoff curve number for moisture condition II (CN2), etc. as shown in the table.

\section{**Insert Table 1 here**}

Table 2 shows the performance evaluation result of the model for calibration (1996-2004) and validation (2005-2007). The coefficient of determination $\left(\mathrm{R}^{2}\right)$ was found to be 0.85 and 0.87 
respectively for calibration and validation, the NSE equalled to 0.85 in both runs, and Percent bias was -2.5 and -5.4 respectively, for those runs. Based on the values of $\mathrm{R}^{2}$, NSE and PBIAS from above table and performance rating criteria provided by (Moriasi et al., 2007), the model showed a reliable estimate even in daily time step for both calibration and validation as comparable to other studies (Singh et al., 2021a). The p-factor for both calibration and validation period were found to be 0.84 , whereas the r-factor for those periods were 0.28 and 0.38 respectively, both within a quite good acceptable range (Singh et al., 2021a; Jain et al., 2017).

\section{**Insert Table 2 here**}

The simulated daily discharge data provided by the model in each iteration was further calibrated with the help of daily observed discharge in such a way that both data in next iteration tended to become closer and of a similar trend as far as possible. the time series plot between observed daily discharge data and the final simulated daily discharge data at Majhitar outlet has shown in Figure 4 along with basin average daily precipitation records. The average monthly observed and simulated streamflow at Majhitar station shows identical representation, as shown in Figure 5a. To highlights the variations in observed and modeled discharge data points, a scatter plot has been drawn as shown in Figure 5b, which demonstrated that the slope of two sets of data is 0.91 , which is nearly 450 and $\mathrm{R} 2$ is equal to 0.86 .

\section{**Insert Figure 4 here**}

From the graphs, it is also found that the base flows of both hydrographs are almost equal in most of the time of the study. The statistical and graphical results by the model indicated satisfying streamflow simulations for both calibration and validation periods at the outlet location. However, it can also be observed that the runoff slightly underestimated during the extreme flow conditions. The reason could be that the curve number method is not able to 
predict accurate runoff for a day that experience several extreme high storms, especially over the HRUs which are corresponded to steep slopes and same observations previous notified by Dhami et al. (2018) and Singh and Goyal (2017). In this study, we used the modified CN method (Singh and Goyal, 2017) which is adjusted for slopes. Therefore, most of high streamflow peaks have been captured well, but it is also notified that during an extreme high storm, because of the presence of steep slopes, several peaks are not captured well (Figure 4). If a single day experienced several storms, the level of soil moisture and the respective runoff curve number might vary from one storm to another (Kim and Lee, 2008). The CN method characterised a rainfall event as the sum of all rainfall that occurs for one day, and this could underestimate the runoff (Choi et al., 2002).

\section{**Insert Figure 5 here**}

The above findings can be considered significant for the assessment of water resources and water balance study of the Tamor basin, especially in Himalayan regions. Further, the result showed that the SWAT model could be applied efficiently in the mountainous river basin like Tamor Basin for hydrological modelling. Once the model was calibrated and validated successfully by using SWAT-CUP, the model was re-run in Arc-SWAT model for the same study period of 1993-2007 taking the best-fitted values of sensitive parameters obtained during calibration and SWAT output results were analysed to carry out the water balance study. The annual and monthly water balance status of the basin has shown in Figure 6, where that the average annual precipitation is recorded as $2304.85 \mathrm{~mm}$. Out of which, $647.66 \mathrm{~mm}(28.10 \%)$ returns as annual evapotranspiration from the basin. The ET/PCP ratio is computed as 0.281 , and this value is within the acceptable range.

In SWAT, the water yield can be defined the streamflow (or runoff) available at the basin outlet and it is the summation of the surface runoff, lateral flow and return flow. Annual water yield 
at the basin outlet is computed as $1511.13 \mathrm{~mm}$, out of which $804.45 \mathrm{~mm}$ is due to surface runoff, which occurs along a sloping terrain and accounts for $34.90 \%$ of total precipitation and $53.23 \%$ of total water yield. Lateral subsurface flow, which originates below the surface but above the aquifer zone, contributes $68.38 \mathrm{~mm}$ (only $2.97 \%$ of total precipitation and about $4.53 \%$ of total water yield). The remaining flow is assisted by return flow originated from a shallow aquifer which is $462.05 \mathrm{~mm}$ ( $20.05 \%$ of total precipitation and about $30.57 \%$ of total water yield). By this way, the average annual runoff volume available at the basin at Majhitar outlet of the basin is found to be $6.25 \mathrm{BCM}$.

Similarly, around $176.97 \mathrm{~mm}$ of average yearly precipitation goes to the deep aquifer, which is assumed to contribute to streamflow somewhere outside of the watershed in the form of return flow (Jeffrey G. Arnold et al., 1993). The average CN of the basin is computed as 81.67, which is within the acceptable range for mid and higher mountain region of Nepal (Dhami et al., 2018; B. K. Mishra et al., 2008). From the monthly distribution of water balance components, it is found that $72.39 \%$ of precipitation, $80.68 \%$ of surface runoff and $75.28 \%$ of water yield occurs during four months of monsoon, i.e. from June to September. The evapotranspiration (ET) is computed the highest value in May $(89.19 \mathrm{~mm})$.

Further, the northern sub-basins of Tamor basin are found to have a considerable part of mainly characterized by snowfall during the winter season, because most of subbasins in the northern part are induced by glacier and snow-covered areas. These subbasins, for a couple of months, contribute meltwater to the streamflow. The result shows that during the winter season (e.g. form of snow within the basin (Figure 6a). 
374 There is a wide range of spatial variation of water balance components among various sub-

375 basins can be visualized in Figure $6 \mathrm{~b}$. The sub-basins located at higher altitudes receive comparatively more precipitation in form of snowfall and comprised with ice-sheets and glaciers (Gupta et al., 2019). Therefore, these sub-basins may have less vegetation density and agricultural land, which might have significant influence on ET which is recorded comparatively low and less infiltration due to hard rocks (Gupta et al., 2019). Hence, more surface runoff can be seen in these subbasins such as subbasin 1 to subbasin 8 (Figure $6 b$ ). From the above table, it was also clear that the water yield may not be highest for the sub-basin with the highest runoff.

After a successful calibration of the model by using SWAT-CUP and re-run of the calibrated model in Arc-SWAT model for the study period, a baseline flow for the calculation is received. Precipitation and temperature inputs were provided for the different study period in future whereas remaining inputs were used available by SWAT auto simulation.

\section{**Insert Table 3 here**}

All precipitation and temperature stations within the basin used by the SWAT model were analysed after bias correction. The precipitation and temperature datasets were corrected with reference to the observed data and a comparison has made against the data obtained from the model as well as that obtained after bias correction. After bias correction, the $\mathrm{R}^{2}$ for both precipitation and temperature is increased, and the RMSE is decreased. Further, the biascorrected data showed improved mean and standard deviation than raw data. Table 3 presents the mean, $\mathrm{R}^{2}$, RMSE, and standard deviation (Std. Dev.) of the observed data, raw data (downloaded data before bias correction), and corrected data of Taplejung stations of the basin. The result for other stations also showed the same pattern and trend. Figure $7 \mathrm{a}$ and Figure $7 \mathrm{~b}$ 
show how the temperature and precipitation data obtained from the model becomes closer to observed data after bias correction in Taplejung (Station code-1405) rainfall station.

\section{**Insert Figure 7 here $* *$}

Future predictions of precipitation patterns in study regions are highly crucial for effective water resource management. Averaged precipitation at basin scale was calculated by the methodology defined in the SWAT manual (Abbaspour et al., 2015). The trend of the projected precipitation under two different scenarios for the future periods from 2030 A.D. to 2100 A.D. obtained for CNRM5 and aggregated by the Theisen polygon method is presented in Figure 8. A linear decreasing trend is seen under RCP4.5, and the linear increasing trend is seen under RCP8.5. The slope of the trendline for RCP4.5 and RCP8.5 is found to be -2.664 and -0.71 , respectively. The monthly mean observed and projected precipitation datasets of the basin for all three future decades have shown in Figure 9. The downscaled and bias-corrected results of the future precipitation patterns indicate that it follows the baseline observed trend. Except in May and June, the mean precipitation is projected to be increased in the remaining months in most of scenarios. The highest precipitation is expected in July and August of the 2030s decade by RCP 4.5 scenario. Table 4 presents the changes (\%) in monthly precipitation for scenarios with respect to the baseline observed data. It is predicted that the monthly mean precipitation will be increased in most of the future months in both scenarios. The most extreme change in rainfall would be observed in November of the 2060s decade when the increment is predicted to be $396 \%$ by RCP 4.5 but that in remaining months would be quite lower. Another most affected month will be March, where the projected precipitation would be increased by about $132 \%$ to $161 \%$ under RCP4.5s and $101 \%$ to $179 \%$ under RCP $8.5 \mathrm{~s}$.

\footnotetext{
**Insert Table 4 here**
} 
420 Precipitation is likely to be decreased in most of the scenarios from April to June and in

421 December, but the relative decrease percentage will be quite low with compared to that of

422 increasing periods. The result summarises that the mean monthly precipitation of the basin will

423 be significantly increased in most of the scenarios of winter season except in December,

424 slightly increased in monsoon seasons and slightly decreased in pre-monsoon season. The

425 relative changes in the average annual precipitation of the basin for different climate scenarios

426 compared to the observed data have computed, and the same for Taplejung station is computed

427 (Figure 9a-9d).

428 Similarly, the average annual precipitation of Taplejung station is predicted to be increased in

429 all scenarios in all future decades except for RCP4.5 in the 2030s where it is expected to be 430 decreased by $1.37 \%$. The maximum percentage of increment is expected under RCP4.5 in the 4312030 s by $4.49 \%$. The result indicates that the increment in Taplejung station is very less 432 compared to the overall basin average. Figure 9a shows the average annual snowfall in the 433 basin during observed and under different RCP4.5 and RCP8.5 scenarios. The trendline of both 434 RCPs shows that the amount of snowfall would increase until the 2030s and would decrease continuously for further future periods. It is predicted that the snowfall amount would be reduced significantly under RCP8.5.

Declining the quantity of snowfall will increase the proportion of rainfall, which would reduce the snow melted base flow during low flow periods. The rise in temperature would have more adverse impacts in higher altitude in the northern basin. Higher temperatures would push the permanent snow line northern upwards in the Himalayas (Khadka et al., 2020). 
Taplejung is a DHM station located at an altitude of $1732 \mathrm{~m}$ in the middle hill. Since there are

444 a wide temperature, altitudinal and topographical variations between these two stations, so the effect of elevation vs temperature and precipitation were incorporated in the form of calibration parameters such as temperature lapse rate (TLR) and precipitation lapse rate (PLR) (Khadka et al., 2020; Thayyen and Dimri, 2018). In the case of Taplejung station, the Tmax is predicted to be increased more significantly in May, June and December and the Tmin from July to October than in the other months. For Tmax, except in March of the 2030s by RCP4.5 and for Tmin, except in May of 2030s by RCP4.5, the temperature is predicted to be increased in remaining months of each scenario under study. The result shows that the trend of future temperature would vary among the stations at different altitudes.

As per results, the temperature could increase more under RCP 8.5 in the 2090s and less under RCP 4.5 during the 2030s among various scenarios under this study for both maximum and minimum temperature (Table 5). It is predicted that under RCP4.5, the percent increase in average annual maximum and average annual minimum temperature of Taplejung station for 90s decade would be $7.01 \%$ and $12.43 \%$ respectively and those under RCP4.5 would be $18.10 \%$ and $32.7 \%$ respectively. By $2100 \mathrm{AD}$, the average annual maximum temperature at the station is predicted to be shifted from $20.950 \mathrm{C}$ to $22.420 \mathrm{C}$ and $24.740 \mathrm{C}$ under RCP4.5 and RCP8.5 respectively, and the average annual minimum temperature is predicted to be shifted from $-2.510 \mathrm{C}$ to $0.260 \mathrm{C}$ and $2.770 \mathrm{C}$ respectively. Due to these variations in temperature, the enhanced variability in precipitation can be clearly seen. Similarly, under RCP4.5, the per cent increase in average annual maximum and average annual minimum temperature for 90 s decade would be $20.6 \%$ and $89.5 \%$ respectively, and those under RCP 8.5 would be $60.1 \%$ and $210.2 \%$ respectively (Table 5). The worst-case among all scenarios would be for a change in average annual minimum temperature in the 2090 s by RCP8.5 where the value from the observed baseline period would be shifted from $-2.50 \mathrm{C}$ to $+5.30 \mathrm{C}$. 
The result shows that the percent rise in temperature will be very high in the stations at higher altitude. So, it is expected that the increased temperatures would push the permanent snow line northern upwards to the higher altitude and less precipitation would take place in the form of snowfall. Obviously, the increment is higher under RCP 8.5 than under RCP 4.5 for all decades. And it is also found that under RCP8.5, the per cent change in temperature in the 2060s will be even more than that in 2090s under RCP4.5. Further, the daily minimum temperature will be increased with a higher percentage than the daily maximum temperature in all stations for all scenarios. So, the Himalayas which are at higher altitude would be very adversely affected by global warming.

\section{**Insert Table 6 here**}

One of the main objectives of this study is to access the water availability at the main outlet of the basin, i.e. at the outlet of sub-basin number 15 ('O15'). The simulated streamflow for the outlet 'O15' and water balance components of the basin for different future climate scenarios was determined by running Arc-SWAT model by loading future precipitation and temperature data as discussed earlier. The average annual values of the major water balance components of the basin such as precipitation, water yield and evapotranspiration under all future scenarios are tabulated in Table 6.

\section{**Insert Table 7 here**}

The changes in major water balance components mentioned above, with relative to the baseline observed data (Figure 10). The result shows that the average annual basin precipitation and average annual basin surface runoff will be increased in all scenarios except in the 2090s under RCP 4.5 when it would be slightly decreased. Average annual ET will be decreased under both scenarios in the 2030s and will be increased in the remaining scenarios. Most surprisingly, ET 
would be increased by $15.20 \%$ under RCP8.5 in the 2090s. The water yield at 'O15' outlet will be increased under both scenarios in the 2030s and 2060s and decreased under both scenarios in 2090s. The maximum water would be available in the 2030s under RCP 8.5 with the average annual value of $1737.50 \mathrm{~mm}$. The total annual water volume available at the outlet for the baseline period of 1996-2007, as discussed earlier, was 6.255 BMC which is equivalent to $231.9 \mathrm{~m}^{3} / \mathrm{s}$, as shown in Figure 9a. Similarly, the annual water volume for different future scenarios, along with the baseline period, is shown in Figure 9b. The total annual water available at the outlet predicted under RCP4.5 and RCP8.5 are 6.98 BCM, 7.19 BCM in the 2030s, 6.71 BCM and 6.41 BCM in 2060s and 6.12 BCM and 6.14 BCM in 2090s. The result shows that the average annual water quantity will be increased in the 2030s and 2060s but would be slightly decreased in 2090s under both scenarios (Figures 10c and 10d).

Figure 11 shows the monthly mean flow at the main outlet for the baseline period under different future scenarios. It is expected that the flow pattern in the future will be like the baseline flow under all scenarios. The peak flow will not shift from August but will be declined in all scenarios except under RCP8.5 in the 2030s and RCP4.5 in the 2060s. The baseflow will be dramatically increased in all scenarios, and the minimum flow month will be shifted from March to February.

\section{**Insert Figure 10 here**}

The relative changes in the average monthly streamflow of all scenarios with respect to the observed discharge are tabulated in Table 7. At the monthly analysis level, all the RCP4.5s and RCP8.5s scenarios projected that the runoff would increase from November to May. In June, other scenarios than RCP8.5 for the 2030s and 2090s predicted an increase in streamflow. In July, other scenarios than RCP8.5 in the 2030s and in October, other scenarios than RCP4.5 in 2030s predicted a decrease in streamflow. In August, other scenarios than RCP8.5 for the 2030s 
and RCP4.5 for 2060s and in September other scenarios than both RCP4.5s for 2030s predicted

517 decrease in streamflow. The maximum increase in streamflow with respect to baseline period would be $130.47 \%$ predicted in April by RCP4.5 in the 2060s. Similarly, the maximum decrease in streamflow with respect to baseline period would be $-24.53 \%$ predicted in July by RCP4.5 in the 2090s. Most of the streamflow during monsoon season would be decreased and that in other seasons would be increased with respect to the base flow. The trend of the projected average annual discharge under the two different scenarios for the future periods from 2030 A.D. to 2100 A.D. is presented in Figure 10d, along with the equation of the slope. A linear decreasing trend is seen under RCP4.5, and an increasing linear trend is observed. The slope of the trendline for RCP4.5 and RCP8.5 is found to be -0.555 and -0.361 , respectively.

**Insert Figure 11 here ${ }^{* *}$

The computation of water availability in the basin is carried out in the form of different percentage of dependable flow available in the basin for the decades of 2030s, 2060s and 2090s for baseline flow and for both RCP4.5 and RCP8.5 emission scenarios. The dependable flow is computed and the FDC plots show the percentage dependable flow at a time. The monthwise Flow Duration Curves (FDC) for the baseline period have shown in Figures 12a and 12b.

532 The plots show (Figures 12a and 12b) that the flow during lean season months like March, 533 February, April would not be significantly decreased as the percentage exceedance is moved from 0 percentile to 100 percentiles but the flows during high flood season in August, July, September would be decreased considerably. The value of Q40 would vary from $34.5 \mathrm{~m}^{3} / \mathrm{s}$ in April to $729 \mathrm{~m}^{3} / \mathrm{s}$ in August whereas the value of Q90 varies from $21.85 \mathrm{~m}^{3} / \mathrm{s}$ in April to 431.3

$537 \mathrm{~m}^{3} / \mathrm{s}$ in August. The result shows that the lowest and highest flow months corresponds to April 538 and August. 
539 This study also includes the assessment of water availability corresponding to firm flow, which 540 is $90 \%$ (Q90) dependable flow, a base flow which is $40 \%$ (Q40) exceedance flow as well as

541 other two major dependable flow percentage as 75\% (Q75) and 99\% (Q99). The comparison 542 plot of those four monthly dependable flows has shown in Figure 13. If we look at those figures, 543 a small variation of dependable flows in different scenarios in different months of the decades 544 can be noticed.

546 The results can be interpreted based on the base period and peak period. The peak is not shifted, and RCP8.5 in the 2030s showed the highest peak values in all scenarios under all percentile flows in August. Flow in July is predicted to be declined in future scenarios as we move from lower percentile to higher percentile monthly flow. Since the base flow during lean months would be increased in future as projected by all scenarios, there would not be many impacts on higher percentile flow. The dependable daily flows at major percentiles are presented in Table 8. The analysis shows that the firm flow corresponding to $90 \%$ dependable flow at the outlet is $34.53 \mathrm{~m} 3 / \mathrm{s}$ and the $40 \%$ exceedance flow is $155.5 \mathrm{~m} 3 / \mathrm{s}$ for the baseline period. All dependable flows are projected to be increased in future scenarios except Q5 and Q25, which are predicted to be declined in most of the scenarios.

557 A minimum of $19.87 \mathrm{~m}^{3} / \mathrm{s}$ flow was available at the outlet during the baseline period and would 558 be at least $24.49,29.02$ and $24.47 \mathrm{~m}^{3} / \mathrm{s}$ predicted by RCP4.5 and at least $29.14,22.29$ and 27.09 $559 \mathrm{~m}^{3} / \mathrm{s}$ predicted by in RCP8.5 in the 2030s, 2060s and 2090s respectively. In the case of Q40, 560 all RCP4.5s are predicted to have better flow than RCP8.5s in all future decades. There would be a considerable increase in Q99 in future scenarios which indicated the increase in minimum 
baseflow of the river, which would have better consequences in terms of water utilisation in future.

The daily flow duration curve of the baseline period and under all future scenarios is further illustrated by Figure (12b), along with magnifying FDCs from 50\% to $100 \%$. Excluding the probability of exceedance from $3 \%$ to $33 \%$, the baseline flow at the remaining probability of exceedance would be lesser than all other future scenarios. Generally, Run of River type Hydropower projects are designed based on Q40 in Nepal, and Q40 flow is projected to be increased on the future, which would enhance the hydropower production capacity in future.

\section{Conclusions}

The present research work has been performed over the Tamor river basin Nepal for the assessment of historical versus future water availability. For this purpose, the SWAT modeling integrating climate model datasets was performed successfully. The advanced stochastic optimization tool SWAT-CUP was utilized, and the optimized parameters were used to simulate and predict water availabilities within the basin. The model performance was found quite well performed on both graphically and statistically for daily time scale. The study observations showed that the average monthly maximum and average monthly minimum temperature for all future scenarios than the baseline period for all the stations will rise significantly. The percent rise of temperature will be more for the stations at a higher altitude. The average maximum and minimum temperature of Taplejung station at $1732 \mathrm{~m}$ are projected to be increased by $3.800 \mathrm{C}$ and $3.820 \mathrm{C}$. Further, the percent rise would be more for the minimum temperature than the maximum temperature. It is obvious that the RCP8.5 hits more adversely than RCP4.5. It is predicted that the percentage change in temperature in the 2060s under 
will have significant impacts on Tamor river basin, especially over the Northern region which is mostly corresponded to snow and glaciers.

The result of the study shows that the average annual water quantity would be increased in the 2030s and 2060s but would be slightly decreased in 2090s under both emission scenarios. From the monthly distribution of water balance components, it is found that $72.39 \%$ of precipitation, $80.68 \%$ of surface runoff and $75.28 \%$ of water yield occurs during four months of monsoon, i.e. from June to September. But the evapotranspiration is found to have the highest value of $89.19 \mathrm{~mm}$ in May. The average annual basin precipitation is projected to be increased in all scenarios. The sub-basins located at higher altitude receive comparatively more precipitation and hence more surface runoff will be there in future as predicted.

During the winter season, a considerable part of the precipitation takes place in the form of snowfall within the basin with a maximum of $41.39 \%$ snowfall in February and $40.58 \%$ in January. During monsoon season, a minimal amount of snowfall occurs in the basin. Both pathways predicted increase in average annual snowfall in the basin till the 2030s and started declining for further future periods. It is predicted that the snowfall amount would be reduced significantly under RCP8.5. Decreasing the quantity of snowfall would result in increasing the proportion of rainfall which would reduce snow melted base flow during low flow periods. It is expected that the higher temperatures would push the permanent snow line northern upwards to the higher altitude, less precipitation would take place in the form of snowfall and finally, there would be minimal snowfall in the sub-basins by $2100 \mathrm{AD}$ under both scenarios.

The flow during lean season months like March, February, April would not be significantly decreased as the percentage exceedance is moved towards 100 percentiles but the flows during high flood season in August, July, September would be significantly decreased. Since the base flow during lean months would be increased in future as projected by all scenarios, there would 
not be many impacts on higher percentile flows. Excluding the probability of exceedance from $3 \%$ to $33 \%$, all percentiles in future scenarios are predicted to be increased than that on baseline flow. Generally, Run of River type Hydropower projects are designed based on Q40 in Nepal, and Q40 flow is projected to be increased on the future, which would enhance the hydropower production capacity in future.

The assessment of water availability at the main outlet of the basin would be very useful for the study of the hydropower potential since a very high dam of about $208 \mathrm{~m}$ is proposed at this location for the construction of Tamor Storage Hydroelectric Project. Similarly, the projected future streamflow would further help to understand the future pattern and future water potential of the river at this outlet. The present research findings would be helpful to make guidelines and plans for the integrated water resources management over the basin and its environ. Since, the Nepalese Himalayan River basins are less explored and therefore, the methods and approach used in this study can be helpful to explore the water resources availability in other river basins in Nepal and also for the other Himalayan River basins.

\section{Acknowledgement}

First, we are thankful to Indian Institute of Technology Roorkee and National Institute of Hydrology Roorkee for providing the necessary facilities to complete all the task under the present research work. We are grateful to DHM Nepal, NASA NEXGDDP project team, FAO USA group, IPCC portals, USGS USA and SWAT portal for providing the various number of datasets for the completion of the research work. There was no specific funding agency was involved in the present research work.

\section{Conflict of Interest}

The authors have found no conflict of interest for the present research work. 
635

636

637

638

639

640

641

642

643

644

645

646

647

648

649

650

651

652

653

654

655

656

Aawar, T. and Khare, D., 2020. Assessment of climate change impacts on streamflow through hydrological model using SWAT model: a case study of Afghanistan. Modeling Earth Systems and Environment, 6(3), pp.1427-1437.

Abbaspour, K. C. (2015). SWAT-CUP Calibration and Uncertainty Programs user mannual. In Science And Technology.

Agrawala, S., Raksakulthai, V., Larsen, P., Smith, J., \& Reynolds, J. (2003). Development and climate change in Nepal: focus on water resources and hydropower. Oecd, 1-64. https://doi.org/10.1111/j.1475-4762.2009.00911.x

Arnold, J. G., Moriasi, D. N., Gassman, P. W., Abbaspour, K. C., White, M. J., Srinivasan, R., Santhi, C., Harmel, R. D., Van Griensven, A., Van Liew, M. W., Kannan, N., \& Jha, M. K. (2012). SWAT: Model use, calibration, and validation. Transactions of the ASABE, 55(4), $1491-1508$.

Arnold, J. G., Muttiah, R. S., Srinivasan, R., \& Allen, P. M. (2000). Regional estimation of base flow and groundwater recharge in the Upper Mississippi river basin. Journal of Hydrology, 227(1-4), 21-40. https://doi.org/10.1016/S0022-1694(99)00139-0

Arnold, J. G., Srinivasan, R., Muttiah, R. S., \& Williams, J. R. (1998). Large area hydrologic modeling and assessment part I: Model development. In Journal of the American Water Resources Association (Vol. 34, Issue 1, pp. 73-89). https://doi.org/10.1111/j.17521688.1998.tb05961.x

Arnold, Jeffrey G., Allen, P. M., \& Bernhardt, G. (1993). A comprehensive surfacegroundwater flow model. Journal of Hydrology. https://doi.org/10.1016/0022-1694(93)90004$\mathrm{S}$ 
657 Biemans, H., Speelman, L. H., Ludwig, F., Moors, E. J., Wiltshire, A. J., Kumar, P., Gerten, 658 D., \& Kabat, P. (2013). Future water resources for food production in five South Asian river 659 basins and potential for adaptation - A modeling study. Science of the Total Environment. 660 https://doi.org/10.1016/j.scitotenv.2013.05.092

661 Chai, T. and Draxler, R.R., 2014. Root mean square error (RMSE) or mean absolute error 662 (MAE)?-Arguments against avoiding RMSE in the literature. Geoscientific model 663 development, 7(3), pp.1247-1250.

664 Chen, T., Ren, L., Yuan, F., Yang, X., Jiang, S., Tang, T., Liu, Y., Zhao, C. and Zhang, L., 665 2017. Comparison of spatial interpolation schemes for rainfall data and application in 666 hydrological modeling. Water, 9(5), p.342.

667

Chhetri, R., Kumar, P., Pandey, V.P., Singh, R. and Pandey, S., 2020. Vulnerability assessment of water resources in Hilly Region of Nepal. Sustainable Water Resources Management, 6(3), 669 pp.1-12.

670

Choi et al. (2002). Daily streamflow modelling and assessment based on the curve-number 671 technique. Hydrological Processes, 16(16), 3131-3150. https://doi.org/10.1002/hyp.1092

Dahal et al. (2016). Estimating the Impact of Climate Change on Water Availability in Bagmati Basin, Nepal. Environmental Processes, 3(1), 1-17. https://doi.org/10.1007/s40710-016-0127-

675 Devia, G. K., Ganasri, B. P., \& Dwarakish, G. S. (2015). A Review on Hydrological Models. 676 Aquatic Procedia, 4(December), 1001-1007. https://doi.org/10.1016/j.aqpro.2015.02.126

677 Dhami, B., Himanshu, S. K., Pandey, A., \& Gautam, A. K. (2018). Evaluation of the SWAT 678 model for water balance study of a mountainous snowfed river basin of Nepal. Environmental 679 Earth Sciences, 77(1), 1-20. https://doi.org/10.1007/s12665-017-7210-8 
680

681

682

683

684

685

686

687

688

689

690

691

692

693

694

695

696

697

698

699

700

Douglas-Mankin et al. (2010). Soil and water assessment tool (SWAT) model: Current developments and applications. Transactions of the ASABE, 53(5), 1423-1431. https://doi.org/10.13031/2013.34915

Eckhardt, K., \& Arnold, J. G. (2001). Automatic calibration of a distributed catchment model. Journal of Hydrology, 251(1-2), 103-109. https://doi.org/10.1016/S0022-1694(01)00429-2

Fontaine et al. (2002). Development of a snowfall-snowmelt routine for mountainous terrain for the soil water assessment tool (SWAT). Journal of Hydrology, 262(1-4), 209-223. https://doi.org/10.1016/S0022-1694(02)00029-X

Gassman et al. (2014). Applications of the SWAT Model Special Section: Overview and Insights. Journal of Environmental Quality, 43(1), 1-8. https://doi.org/10.2134/jeq2013.11.0466

Gupta et al. (1999). Status of automatic calibration of Hydrologic models: Comparison with multilevel expert calibration. 4(April), 135-143.

Gupta, A., Kayastha, R.B., Ramanathan, A.L. and Dimri, A.P., 2019. Comparison of hydrological regime of glacierized Marshyangdi and Tamor river basins of Nepal. Environmental Earth Sciences, 78(14), pp.1-15.

Gupta, V., Singh, V. and Jain, M.K., 2020. Assessment of precipitation extremes in India during the 21st century under SSP1-1.9 mitigation scenarios of CMIP6 GCMs. Journal of Hydrology, 590, p.125422.

Gurrapu, S. and Singh, V., 2019. Chapter-13-Uncertainty in climate change studies. National Institute of Hydrology. 
701

702

703

704

705

706

707

708

709

710

711

712

713

714

715

716

717

718

719

720

721

722

Himanshu, S. K., Pandey, A., \& Shrestha, P. (2017). Application of SWAT in an Indian river basin for modeling runoff, sediment and water balance. Environmental Earth Sciences, 76(1), 1-18. https://doi.org/10.1007/s12665-016-6316-8

Jain, S.K., Jain, S.K., Jain, N. and Xu, C.Y., 2017. Hydrologic modeling of a Himalayan mountain basin by using the SWAT mode. Hydrology and Earth System Sciences Discussions, pp.1-26.

Jones, J. A. A. (1999). Climate change and sustainable water resources: Placing the threat of global warming in perspective. Hydrological Sciences Journal, 44(4), 541-557. https://doi.org/10.1080/02626669909492251

Kadel, I., Yamazaki, T., Iwasaki, T., \& Abdillah, M. R. (2018). Projection of future monsoon precipitation over the central himalayas by CMIP5 models under warming scenarios. Climate Research, 75(1), 1-21. https://doi.org/10.3354/cr01497

Kalcic et al. (2015). Defining Soil and Water Assessment Tool (SWAT) hydrologic response units (HRUs) by field boundaries. International Journal of Agricultural and Biological Engineering, 8(3), 1-12. https://doi.org/10.3965/j.ijabe.20150803.951

Khadka, N., Ghimire, S.K., Chen, X., Thakuri, S., Hamal, K., Shrestha, D. and Sharma, S., 2020. Dynamics of maximum snow cover area and snow line altitude across Nepal (2003-2018) using improved MODIS data. Journal of Institute of Science and Technology, 25(2), pp.17-24.

Kim, N. W., \& Lee, J. (2008). Advanced Bash-Scripting Guide An in-depth exploration of the art of shell scripting Table of Contents. Okt 2005 Abrufbar Uber Httpwww Tldp OrgLDPabsabsguide Pdf Zugriff 1112 2005, 2274(November 2008), 2267-2274. https://doi.org/10.1002/hyp 
723

724

725

726

727

728

729

730

731

732

733

734

735

736

737

738

739

740

741

742

743

Kumar, N., Singh, S.K., Srivastava, P.K. and Narsimlu, B., 2017. SWAT Model calibration and uncertainty analysis for streamflow prediction of the Tons River Basin, India, using Sequential Uncertainty Fitting (SUFI-2) algorithm. Modeling Earth Systems and Environment, 3(1), p.30.

Kundu, S., Khare, D., \& Mondal, A. (2017). Individual and combined impacts of future climate and land use changes on the water balance. Ecological Engineering, 105, 42-57. https://doi.org/10.1016/j.ecoleng.2017.04.061

Lin, F., Chen, X. and Yao, H., 2017. Evaluating the use of Nash-Sutcliffe efficiency coefficient in goodness-of-fit measures for daily runoff simulation with SWAT. Journal of Hydrologic Engineering, 22(11), p.05017023.

Mishra, B. K., Takara, K., \& Tachikawa, Y. (2008). NRCS Curve Number based Hydrologic Regionalization of Nepalese River Basins for Flood Frequency Analysis. Annuals of Disaster Prevention Research Institute, Kyoto University, 51(B), 189-195.

Mishra, Y., Nakamura, T., Babel, M. S., Ninsawat, S., \& Ochi, S. (2018). Impact of climate change on water resources of the Bheri River Basin, Nepal. Water (Switzerland), 10(2), 1-21. https://doi.org/10.3390/w10020220

Moradkhani, H., \& Sorooshian, S. (2009). General Review of Rainfall-Runoff Modeling: Model Calibration, Data Assimilation, and Uncertainty Analysis. Hydrological Modelling and the Water Cycle, 1-24. https://doi.org/10.1007/978-3-540-77843-1_1

Moriasi et al. (2007). Model Evaluation Guidelines for Systematic Quantification of Accuracy in Watershed Simulations. 50(3), 885-900. https://doi.org/10.13031/2013.23153 
744 Nash, J. E., \& Sutcliffe, J. V. (1970). River flow forecasting through conceptual models part I - A discussion of principles. Journal of Hydrology, 10(3), 282-290. https://doi.org/10.1016/0022-1694(70)90255-6

747 NEA Nepal. (2018). NEPAL Electricity Authority (NEA) project development department 748 interim feasibility report on Tamor Storage Hydroelectric Project. https://www.nepalindata.com/media/resources/items/13/bTamor-Storage-Hydroelectric-

750 Project.pdf

751 NRCNA. (2012). Climate change: Evidence, impacts, and choices: PDF booklet. In Climate

752 Change: Evidence, Impacts, and Choices: PDF Booklet. https://doi.org/10.17226/14673

753 Pandey et al. (2015). Evaluation du potentiel hydroélectrique utilisant la technologie spatiale 754 et le modèle SWAT pour la rivière Mat, dans le sud Mizoram, Inde. Hydrological Sciences 755 Journal, 60(10), 1651-1665. https://doi.org/10.1080/02626667.2014.943669

756 Pradhanang et al. (2011). Application of SWAT model to assess snowpack development and 757 streamflow in the Cannonsville watershed, New York, USA. Hydrological Processes, 25(21), 758 3268-3277. https://doi.org/10.1002/hyp.8171

Sharma, R. H., \& Shakya, N. M. (2006). Hydrological changes and its impact on water resources of Bagmati watershed, Nepal. Journal of Hydrology, 327(3-4), 315-322. https://doi.org/10.1016/j.jhydrol.2005.11.051

762 Shirmohammadi et al. (2008). Modeling at catchment scale and associated uncertainties. Boreal Environment Research, 13(3), 185-193. Distributed Watershed Models. World Water and Environmental Resources Congress, 40685(January 2004), 3423-3429. https://doi.org/10.1061/40685(2003)116 

Integrated simulation of snow and glacier melt in water and energy balance-based, distributed hydrological modeling framework at Hunza River Basin of Pakistan Karakoram region. Journal of Geophysical Research: Atmospheres, 120(10), pp.4889-4919.

Singh, V. and Goyal, M.K., 2016. Changes in climate extremes by the use of CMIP5 coupled climate models over eastern Himalayas. Environmental Earth Sciences, 75(9), p.839.

Singh, V. and Goyal, M.K., 2017. Curve number modifications and parameterization sensitivity analysis for reducing model uncertainty in simulated and projected streamflows in a Himalayan catchment. Ecological engineering, 108, pp.17-29.

Singh, V. and Goyal, M.K., 2017. Spatio-temporal heterogeneity and changes in extreme precipitation over eastern Himalayan catchments India. Stochastic Environmental Research and Risk Assessment, 31(10), pp.2527-2546.

Singh, V. and Xiaosheng, Q., 2019. Data assimilation for constructing long-term gridded daily rainfall time series over Southeast Asia. Climate Dynamics, 53(5), pp.3289-3313.

Singh, V., \& Goyal, M. K. (2016). Changes in climate extremes by the use of CMIP5 coupled climate models over eastern Himalayas. Environmental Earth Sciences, 75(9), 1-27. https://doi.org/10.1007/s12665-016-5651-0

Singh, V., Jain, S.K. and Goyal, M.K., 2021a. An assessment of snow-glacier melt runoff under climate change scenarios in the Himalayan basin. Stochastic Environmental Research and Risk Assessment, pp.1-26. Himalayan Baspa river basin. Journal of Hydrology, 593, p.125918. 
Singh, V., Jain, S.K. and Singh, P.K., 2019b. Inter-comparisons and applicability of CMIP5 GCMs, RCMs and statistically downscaled NEX-GDDP based precipitation in India. Science of the Total Environment, 697, p.134163.

Singh, V., Sharma, A. and Goyal, M.K., 2019a. Projection of hydro-climatological changes over eastern Himalayan catchment by the evaluation of RegCM4 RCM and CMIP5 GCM models. Hydrology Research, 50(1), pp.117-137.

Spruill et al. (2000). Simulation of daily and monthly stream discharge from small watersheds using the SWAT model. Transactions of the American Society of Agricultural Engineers, 43(6), 1431-1439. https://doi.org/10.13031/2013.3041

Talchabhadel et al. (2020). Spatial and Temporal Variability of Precipitation in Southwestern. 74(5), 289-294.

Thayyen, R.J. and Dimri, A.P., 2018. Slope environmental lapse rate (SELR) of temperature in the monsoon regime of the western Himalaya. Frontiers in Environmental Science, 6, p.42.

Troin, M., \& Caya, D. (2014). Evaluating the SWAT's snow hydrology over a Northern Quebec $\quad$ watershed. Hydrological Processes, 28(4), 1858-1873. https://doi.org/10.1002/hyp.9730

Tuppad et al. (2011). Soil and water assessment tool (swat) hydrologic/water quality model: Extended capability and wider adoption. Transactions of the ASABE, 54(5), 1677-1684. https://doi.org/10.13031/2013.39856

WECS. (2011). (Water and Energy Commission Secretariat). Water resources of Nepal in the context of climate change. 68 . www.wec.gov.np 
810 Williams, J. R., Arnold, J. G., Kiniry, J. R., Gassman, P. W., \& Green, C. H. (2008). History

811 of model development at Temple, Texas. Hydrological Sciences Journal, 53(5), 948-960.

812 https://doi.org/10.1623/hysj.53.5.948

813 Zhang, D., Lin, Q., Chen, X. and Chai, T., 2019. Improved curve number estimation in SWAT

814 by reflecting the effect of rainfall intensity on runoff generation. Water, 11(1), p.163.

815 Zhang, Q., Zhang, Z., Shi, P., Singh, V.P. and Gu, X., 2018. Evaluation of ecological instream

816 flow considering hydrological alterations in the Yellow River basin, China. Global and

817 Planetary Change, 160, pp.61-74.

818

819

820

821

822

823

824

825

826 
Figures

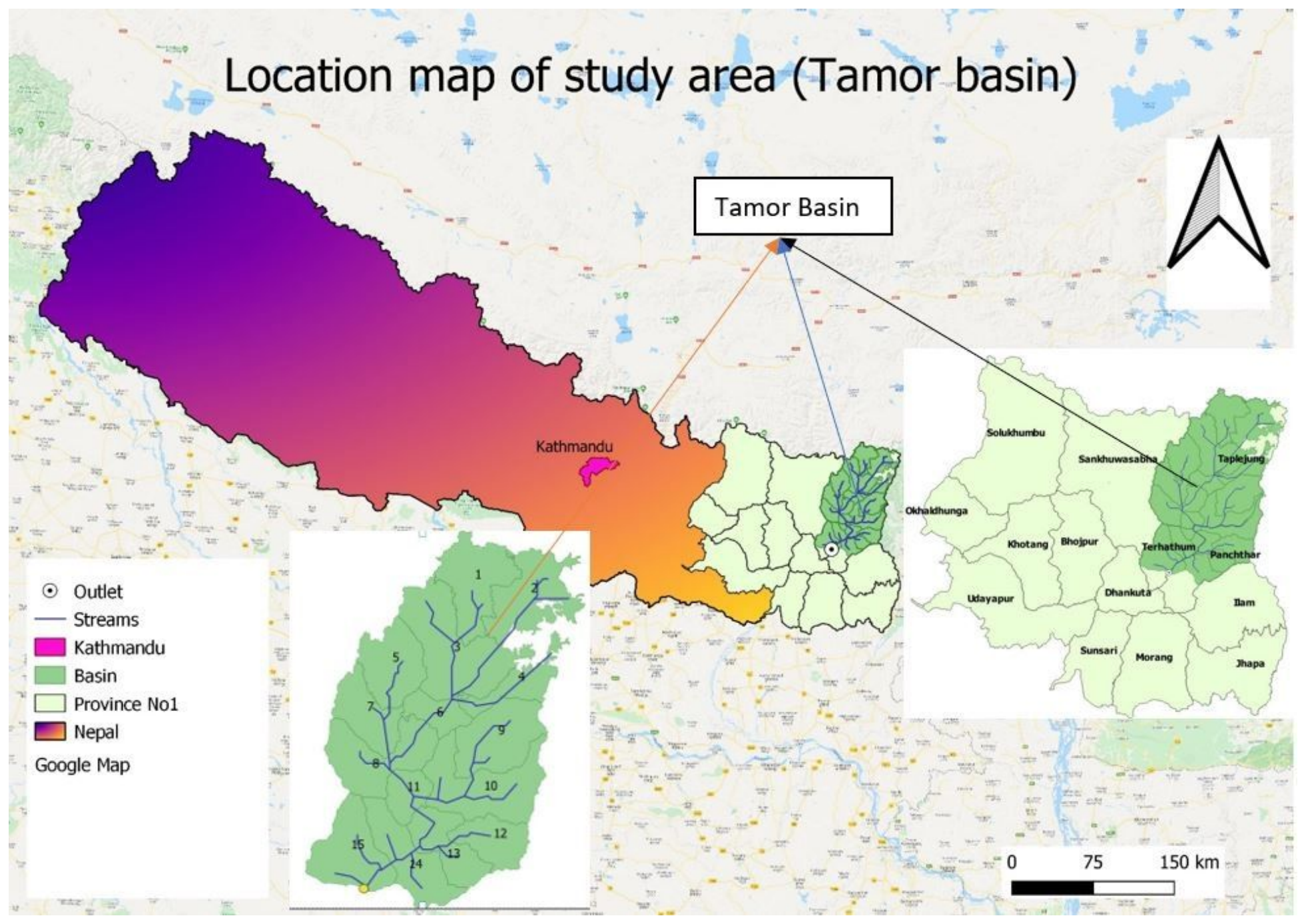

Figure 1

Study area map showing streams and other watershed characteristics. 

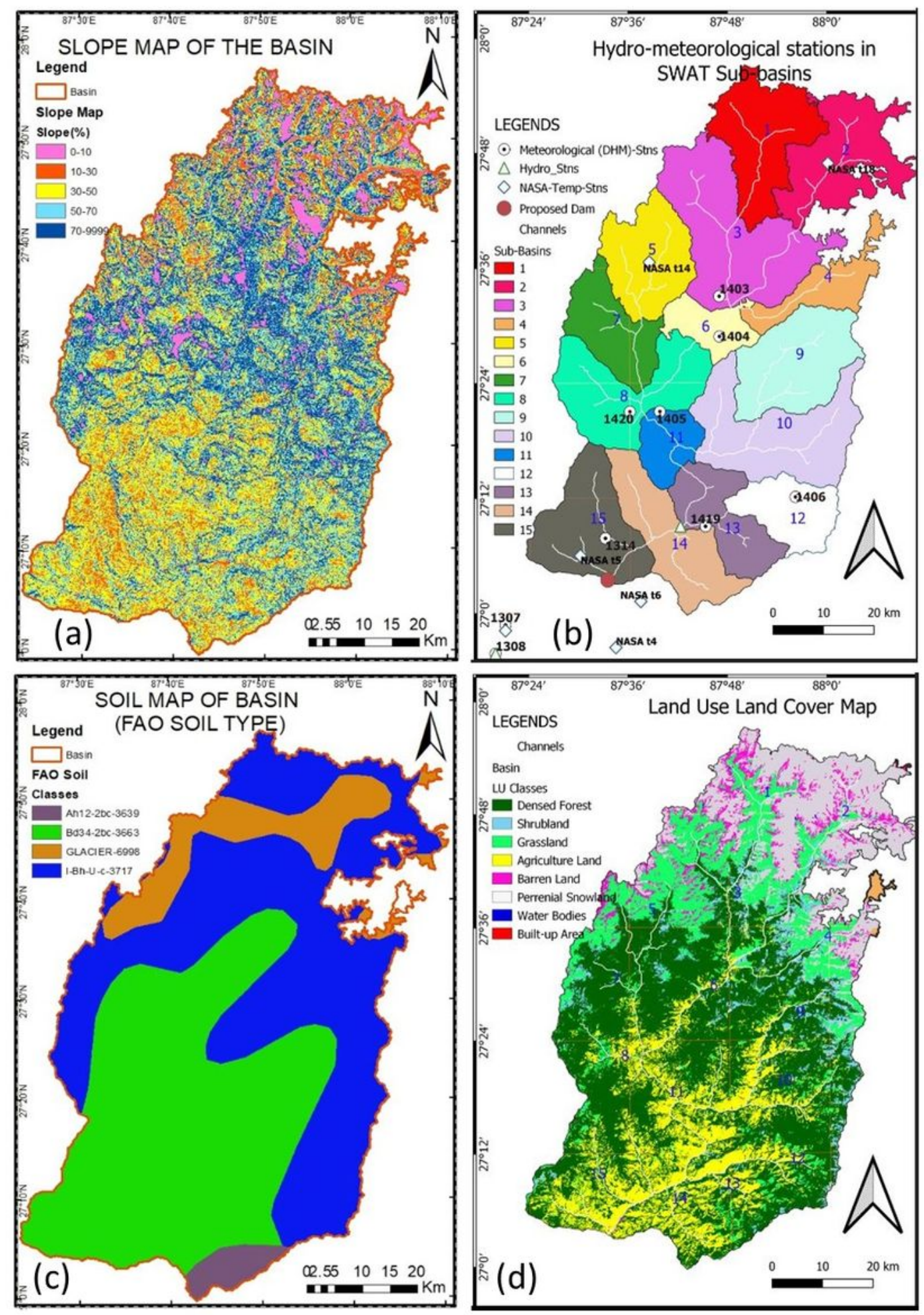

\section{Figure 2}

(a) Slope map, (b) watersheds (or subbasins), (c) soil map and (d) LULC map of the selected study basin. 


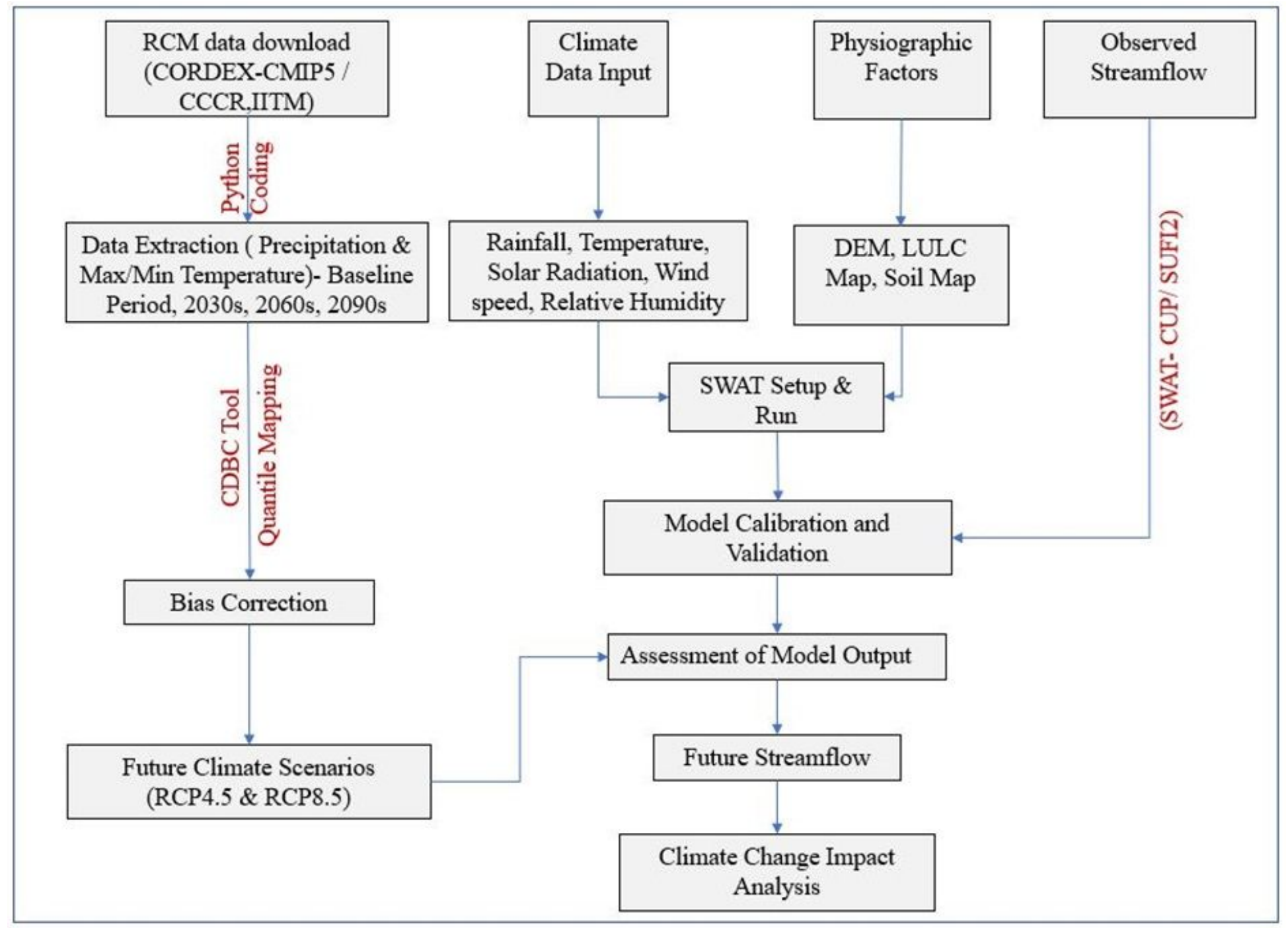

Figure 3

Flow chart for the water balance study of the baseline and the future periods. 


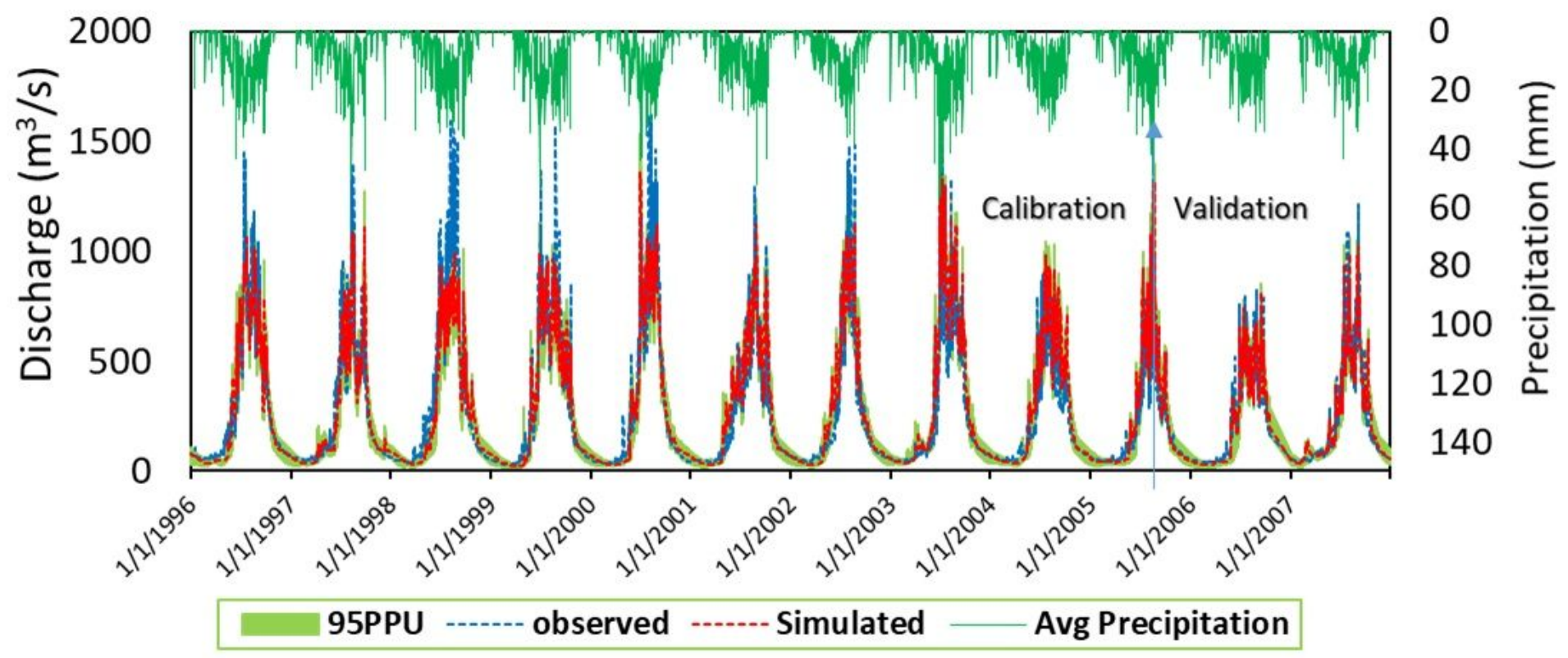

Figure 4

Calibration \& Validation of daily discharge at Majhitar station (1996-2007). 

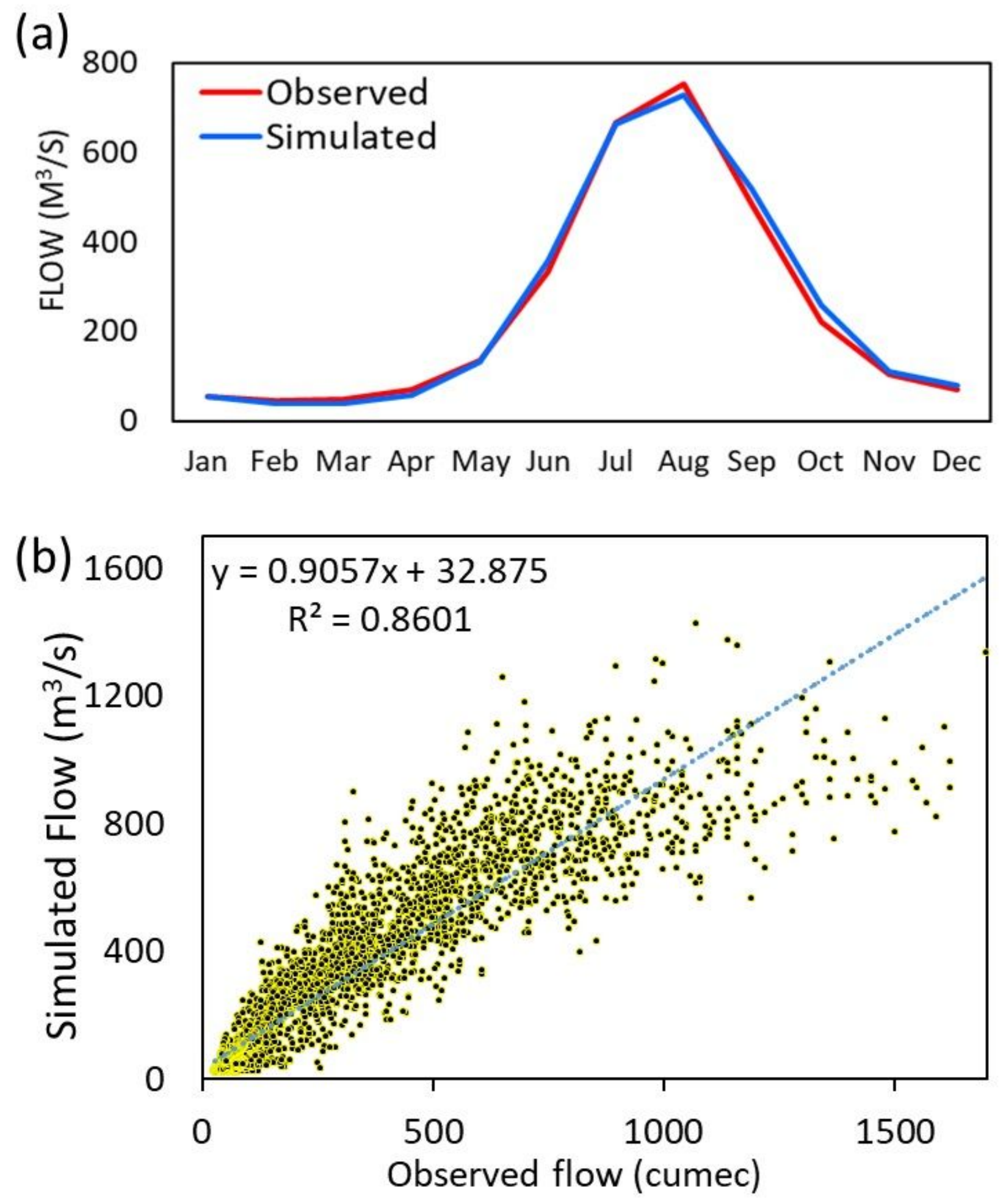

Figure 5

(a) Monthly average discharge hydrograph of observed \& simulated flow and (b) scatter chart of observed and simulated flow. 

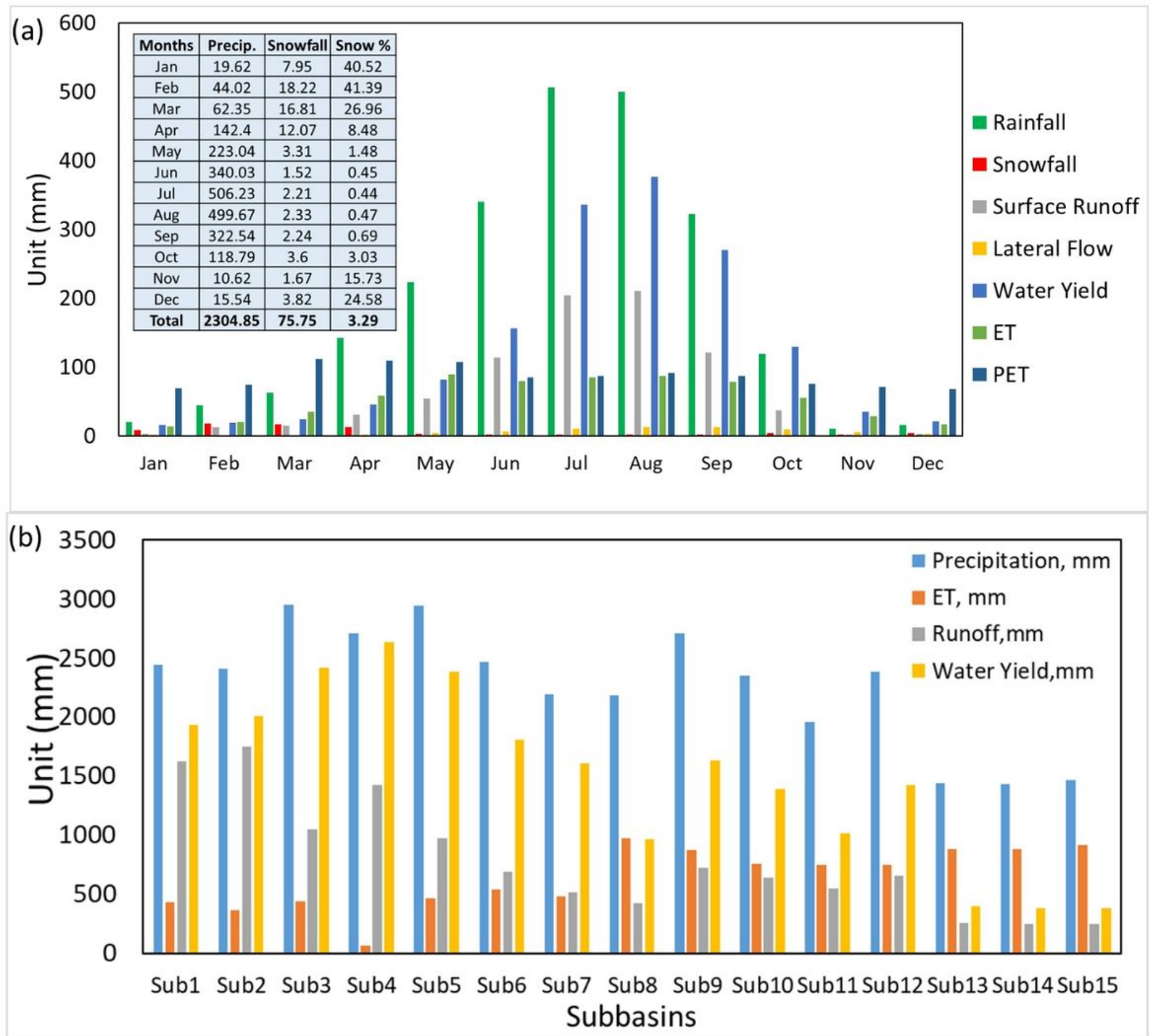

Figure 6

(a) Basin wise monthly mean characteristics of all watershed components (in $\mathrm{mm}$ ) and (b) average annual water balance in the subbasins (in $\mathrm{mm}$ ). 

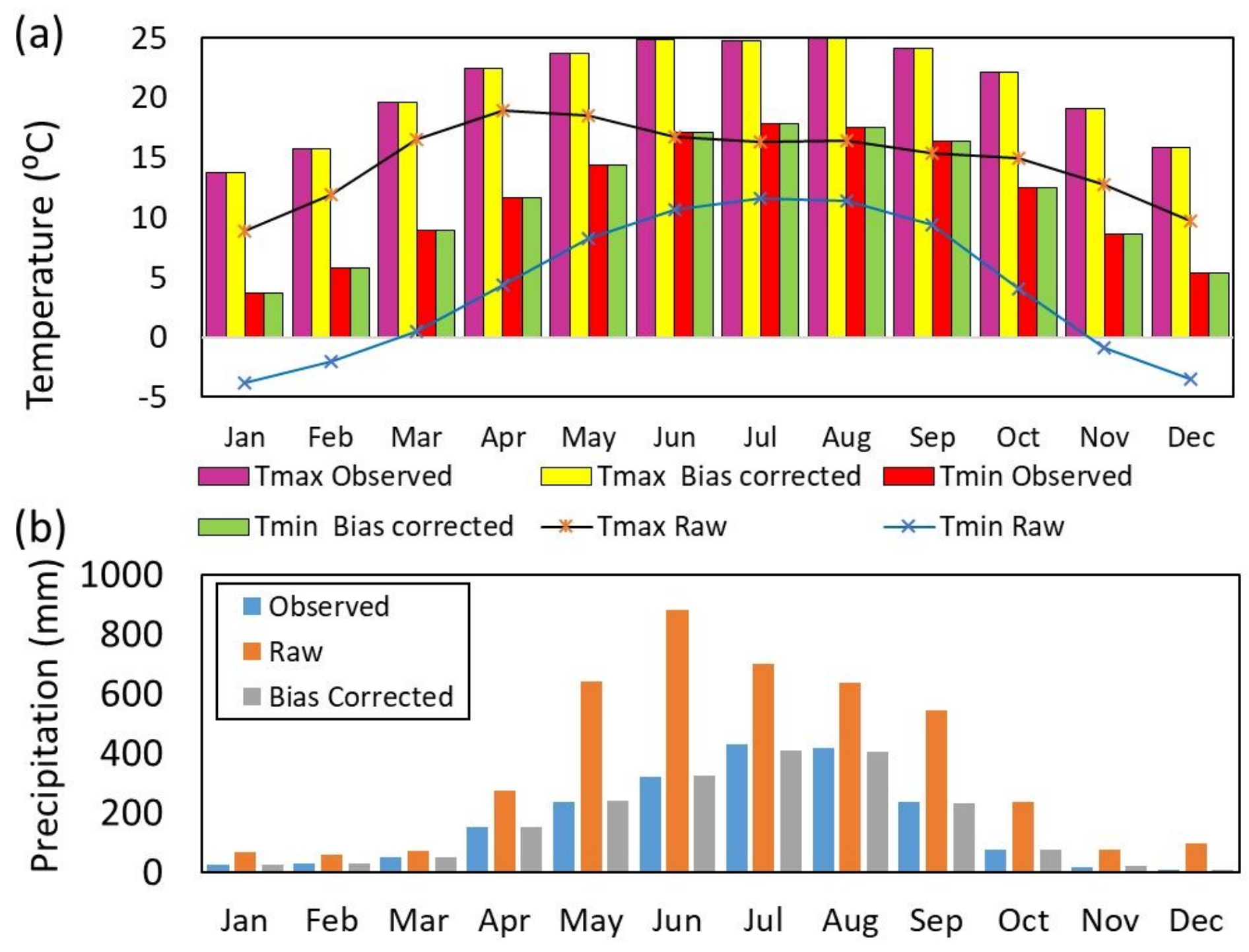

Figure 7

(a) Observed, raw and bias-corrected temperature at Taplejung station and (b) Observed, raw and biascorrected precipitation at the Taplejung station. 


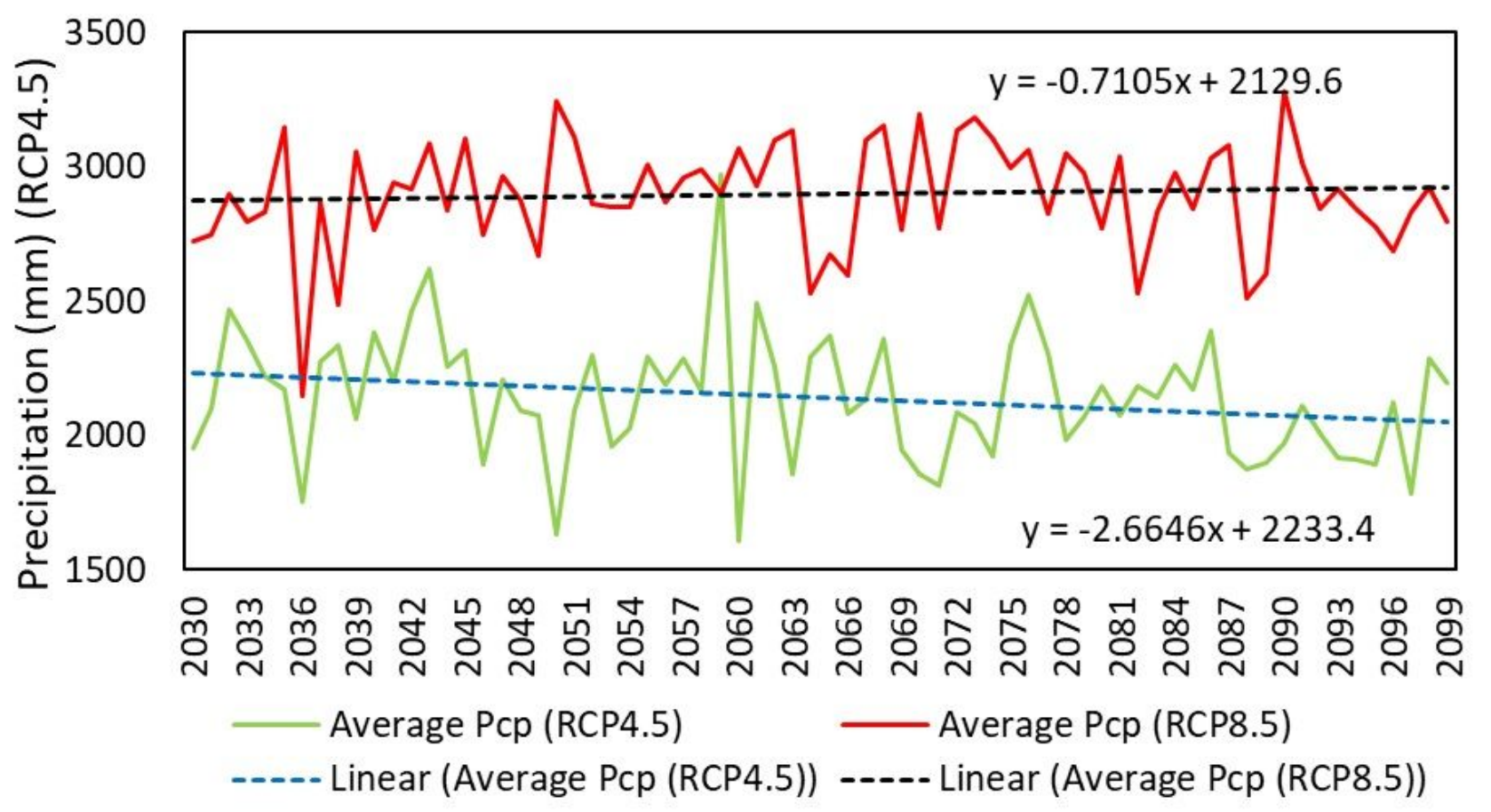

\section{Figure 8}

Future trend of average annual basin precipitation from 2030 to 2100.

(a)

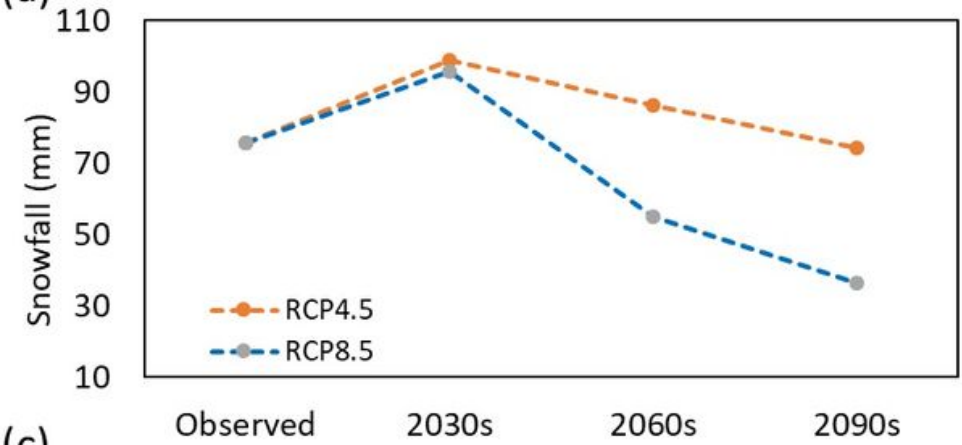

(b)

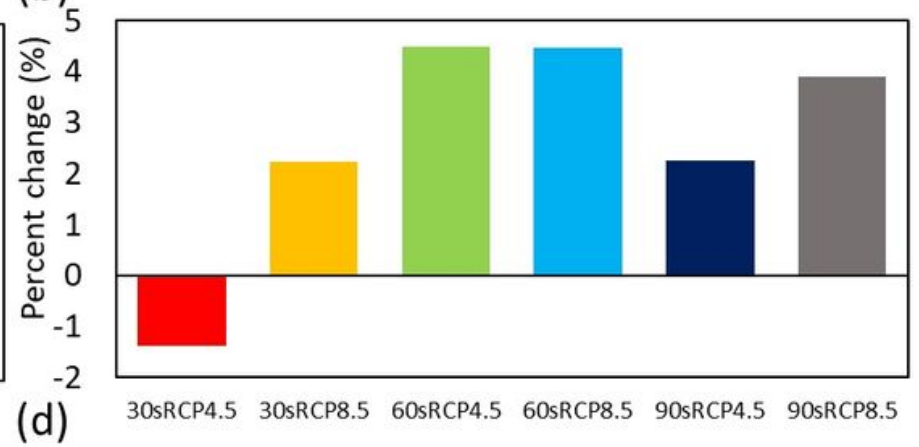

(c)
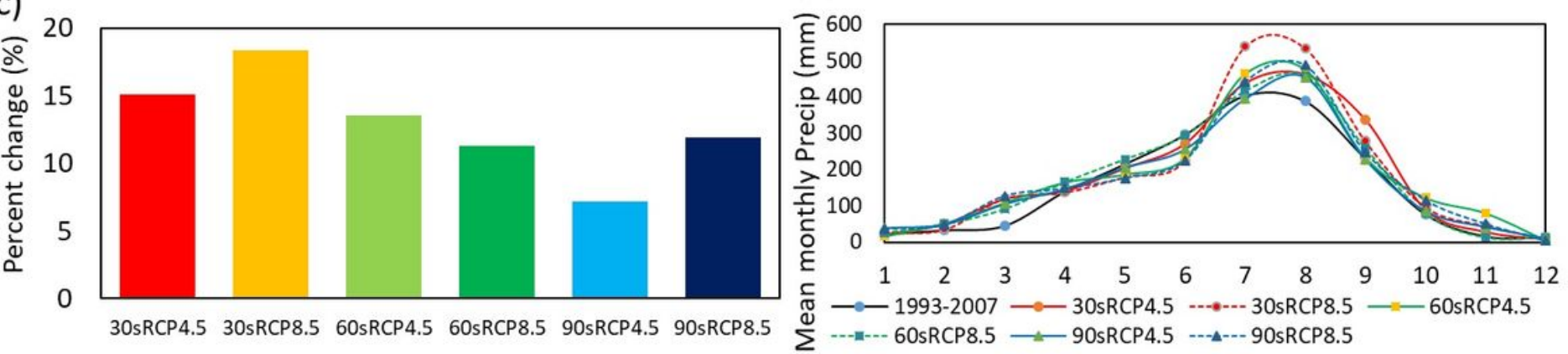

Figure 9

(a) Average annual snowfall in the basin for observed and different future scenarios, (b) percent change in average annual precipitation of Taplejung for future scenarios, (c) percent change in avg. annual basin precipitation of future scenarios with base period and (d) mean monthly basin precipitation of observed period and future scenarios. 
(a)

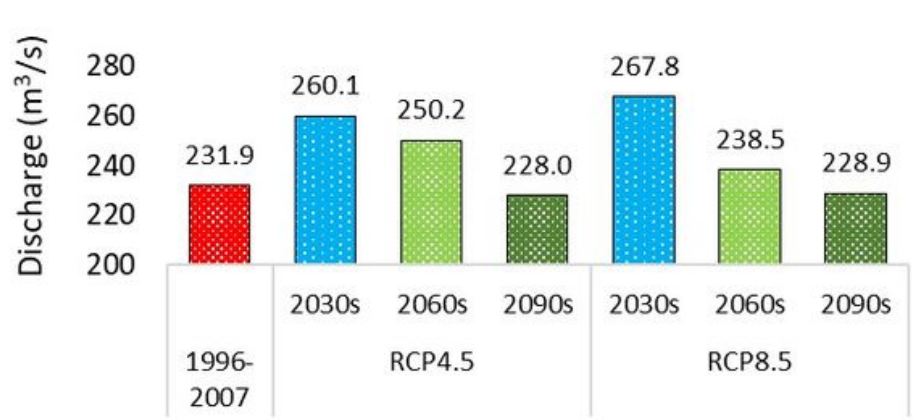

(c)

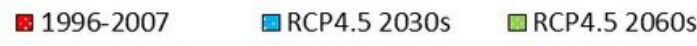
圆RCP4.5 2090s $\square$ RCP8.52030s $\square$ RCP8.5 2060s

(c) $\quad$ RCP8.5 2090s

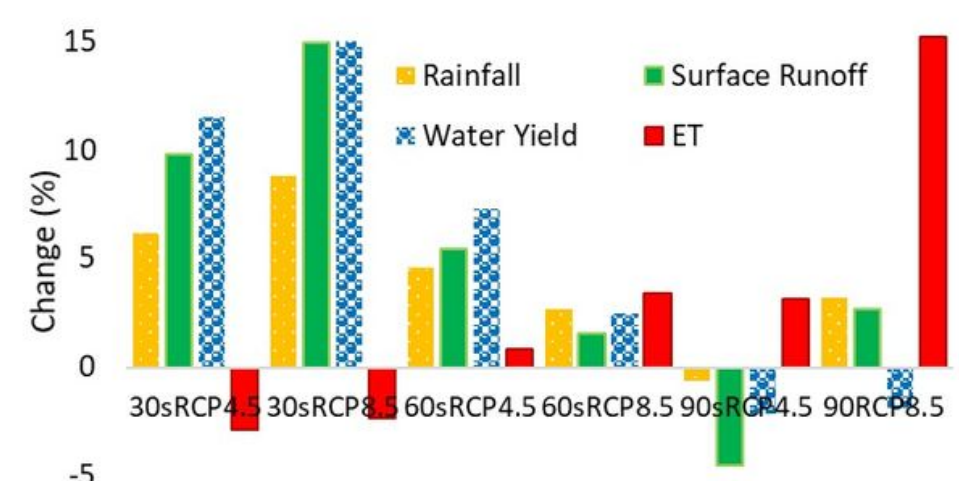

$-5$

$-10$ (b)

7.5

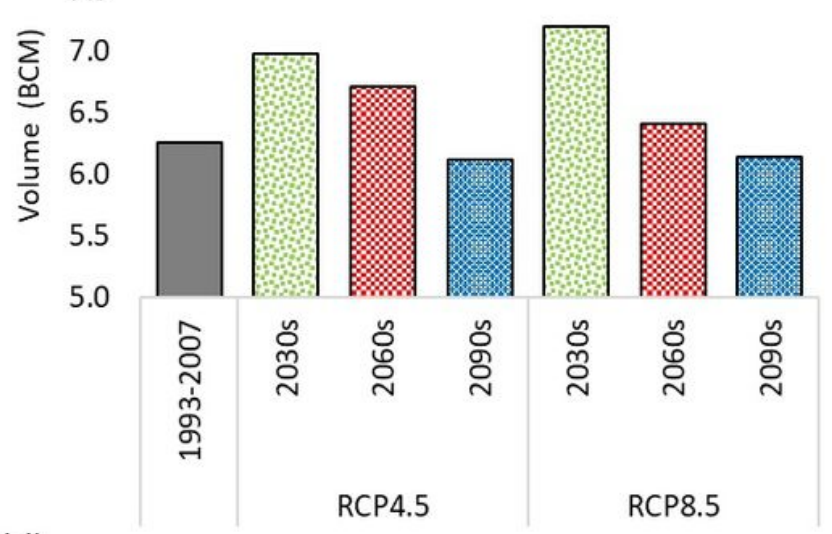

(d)

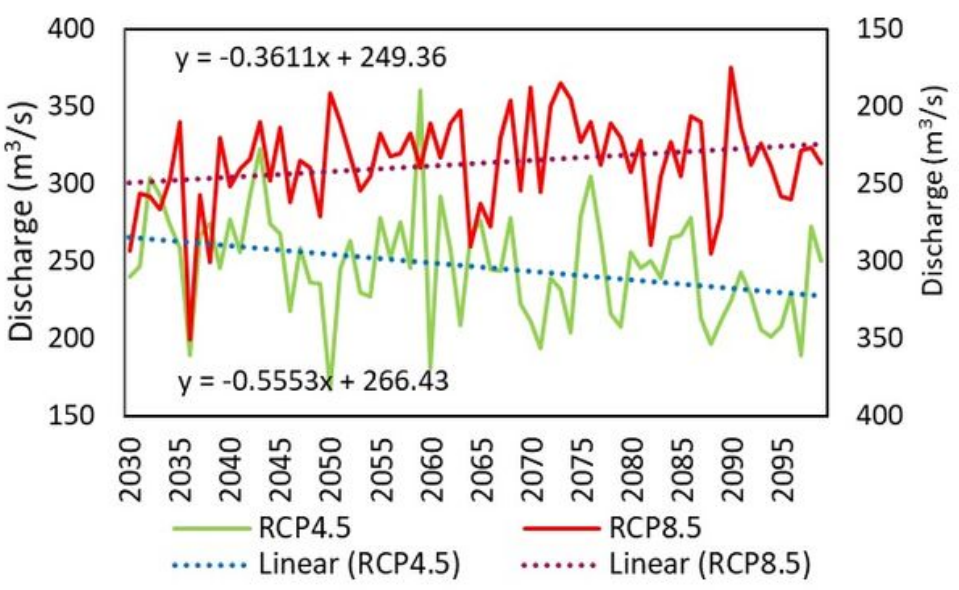

Figure 10

(a) Average Annual Discharge at ' 015 ' outlet, (b) average annual water volume available at ' 015 ' outlet,

(c) percent change in future water balance components and (d) Future trend of average annual streamflow at main outlet from 2030 to 2100 . 


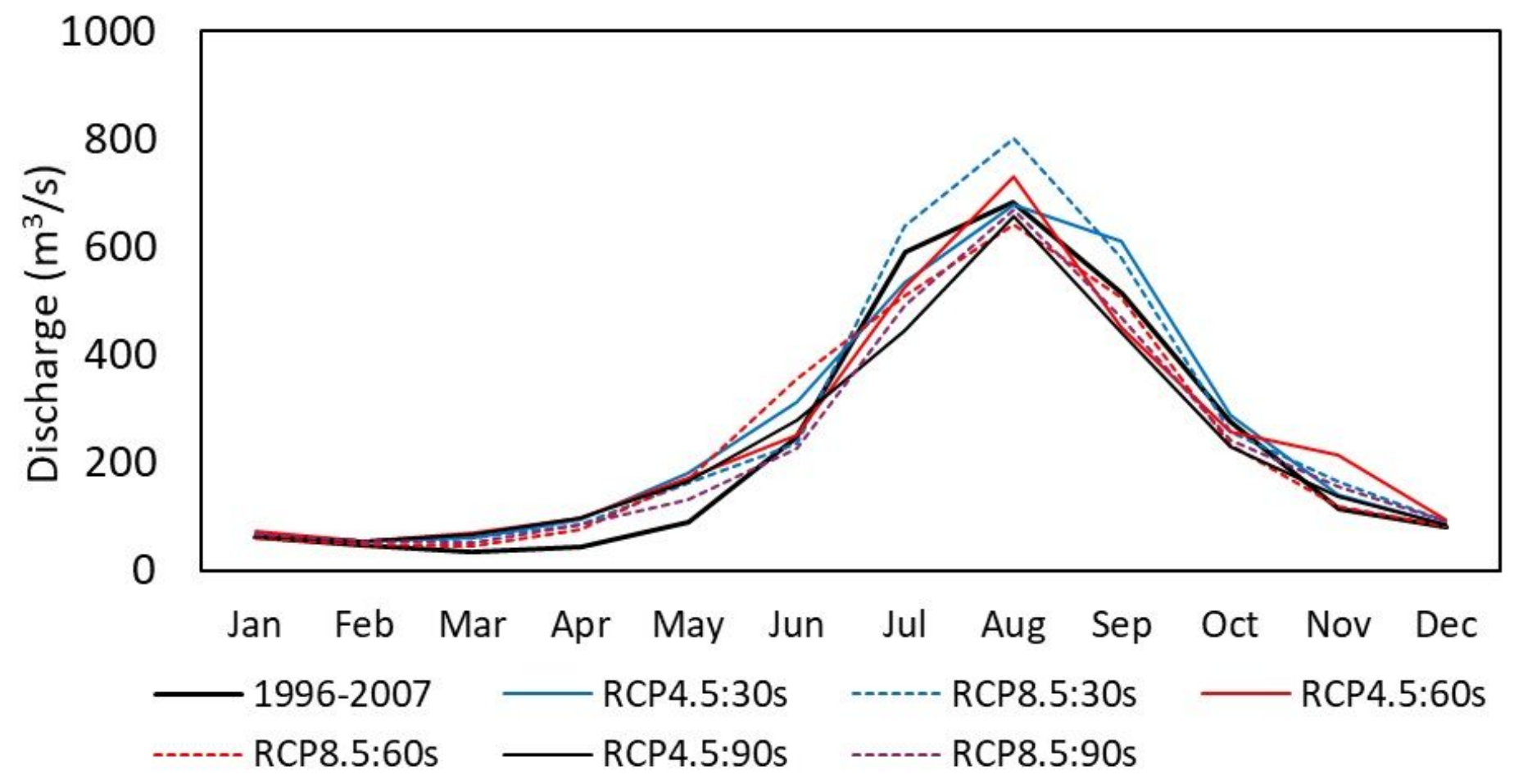

Figure 11

Monthly average streamflow of base period \& different future scenarios. 

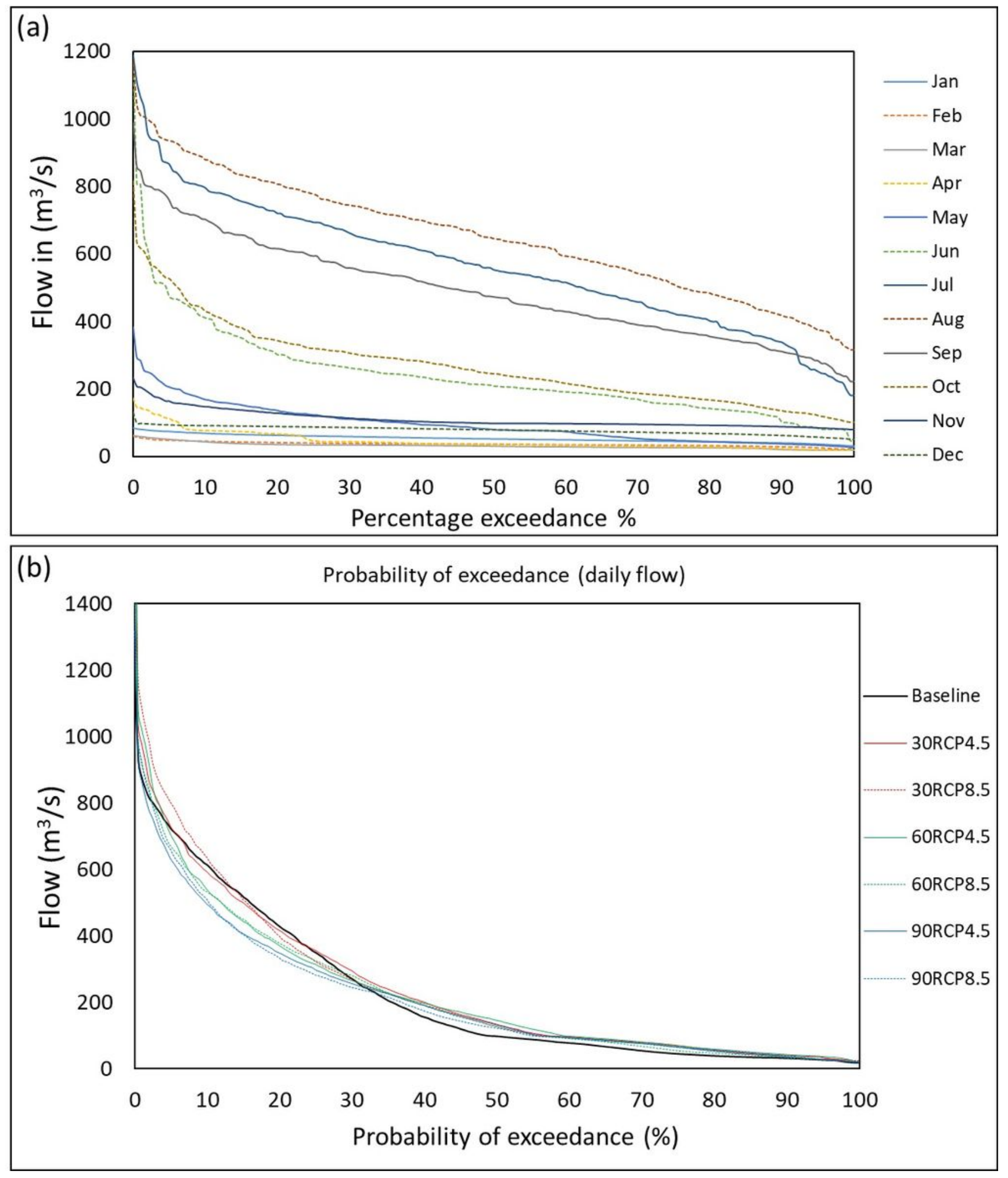

\section{Figure 12}

(a) Month-wise FDCs for the baseline period (1996-2007) and (b) FDC (on daily flow) of baseline period and under future scenarios. 


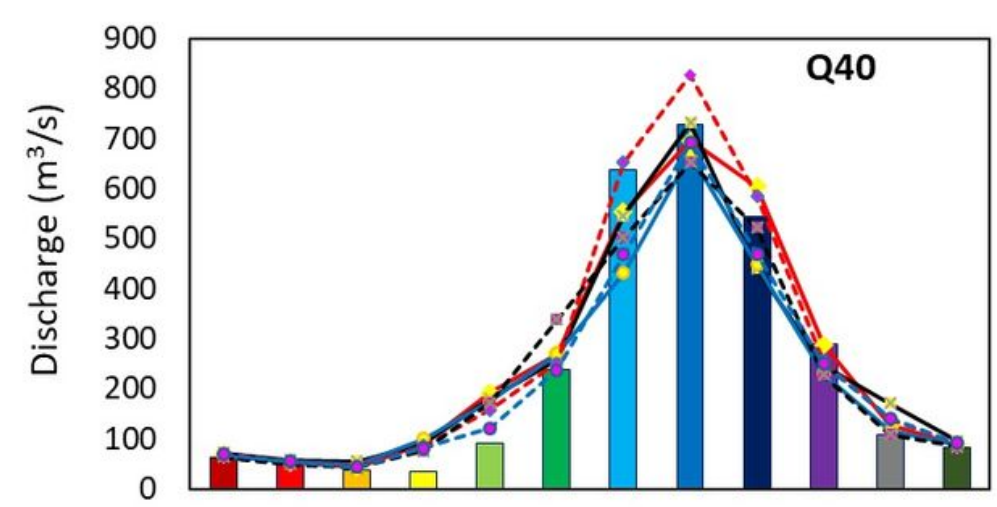

Jan Feb Mar Apr May Jun Jul Aug Sep Oct Nov Dec

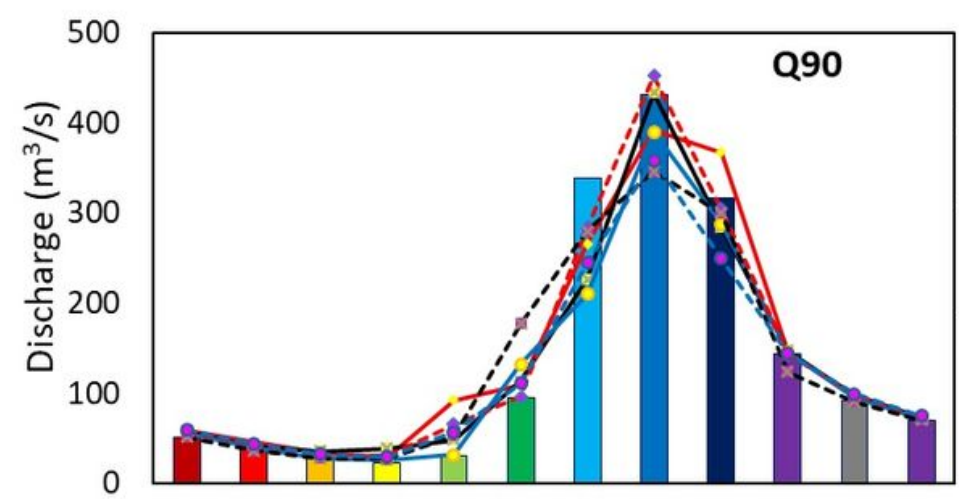

Jan Feb Mar Apr May Jun Jul Aug Sep Oct Nov Dec

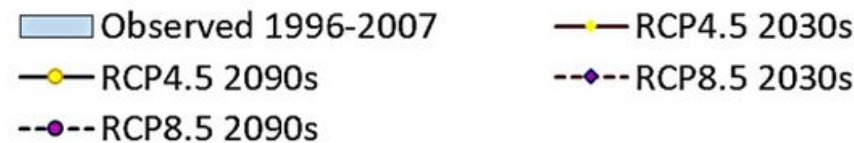

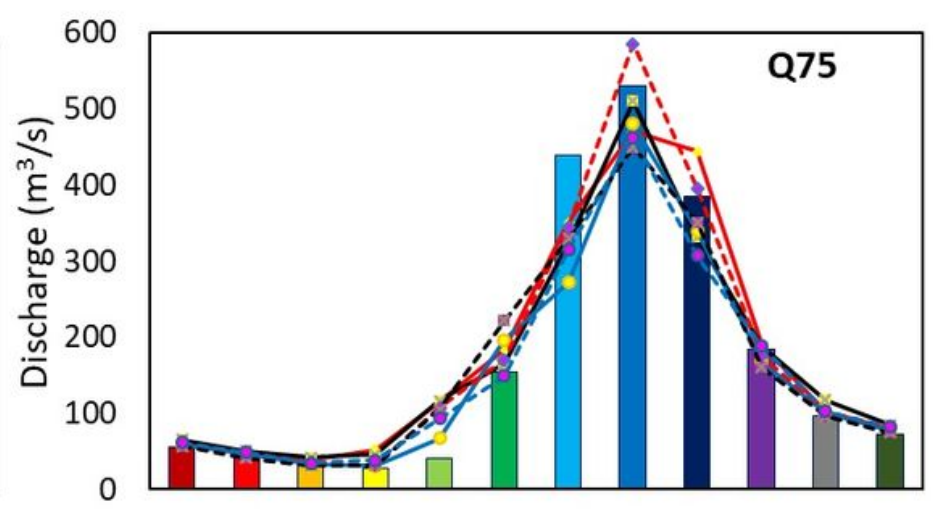

Jan Feb Mar Apr May Jun Jul Aug Sep Oct Nov Dec

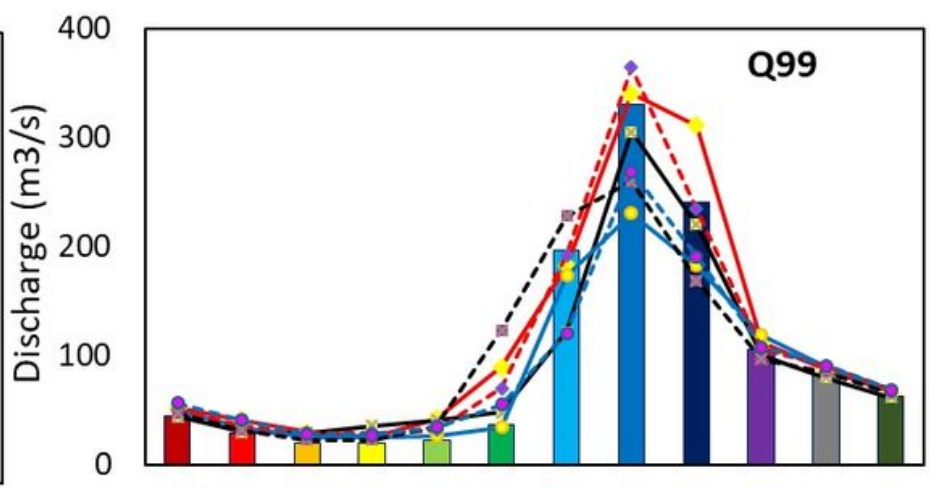

Jan Feb Mar Apr May Jun Jul Aug Sep Oct Nov Dec

Figure 13

Percentile monthly flow at Majhitar outlet for observed and future scenarios.

$-x-$ RCP4.5 2060s

$--1--R C P 8.52060 s$ 